\title{
Yersinia enterocolitica induces epithelial barrier dysfunction through regional tight junction changes in colonic HT-29/B6 cell monolayers
}

\author{
Nina A Hering ${ }^{1,2}$, Jan F Richter ${ }^{3}$, Susanne M Krug ${ }^{3}$, Dorothee Günzel ${ }^{3}$, Anja Fromm ${ }^{1,3}$, Erwin Bohn ${ }^{4}$, Rita Rosenthal ${ }^{3}$, \\ Roland Bücker ${ }^{2}$, Michael Fromm ${ }^{3}$, Hanno Troeger ${ }^{1}$ and Jörg D Schulzke ${ }^{1,2}$
}

Yersinia enterocolitica is a common cause of acute gastroenteritis. This study aimed to clarify the mechanisms leading to barrier dysfunction and diarrhea. Exposure of human colonic HT-29/B6 cells to $Y$. enterocolitica resulted in a decrease in transepithelial resistance from $404 \pm 23$ to $163 \pm 21 \Omega \mathrm{cm}^{2}(P<0.001)$ in parallel with an increase in mannitol $(182 \mathrm{Da})$ and fluorescein $(332 \mathrm{Da})$ permeability, whereas short circuit current did not change. This effect was time dependent, required the presence of living bacteria, could not be triggered by bacterial supernatants and was not due to Yersinia outer proteins. Concomitantly, Y. enterocolitica induced necrosis as indicated by an increase in lactate dehydrogenase-release, whereas epithelial apoptosis was not upregulated. Local changes in conductivity were detected by conductance scanning, indicating 'leaky regions' within the epithelium that were visualized by biotinylation and confocal microscopy. In these regions, claudin-3 and -4 and, especially claudin-8, were redistributed off the tight junction (TJ) into the cytoplasm. In addition, the expression of claudin-2, $-3,-8,-10$ and ZO-1 was diminished as quantified by immunoblotting. Moreover, we found claudin-8 to be regulated by the c-Jun N-terminal kinase, the inhibition of which attenuated the $Y$. enterocolitica-induced decrease in transepithelial resistance and restored claudin-8 protein level. In conclusion, barrier dysfunction in $Y$. enterocolitica infection is due to circumscribed epithelial TJ protein changes and necrotic cell loss, as a consequence of which leak flux diarrhea and antigen-uptake provoking extraintestinal arthritis may be triggered.

Laboratory Investigation (2011) 91, 310-324; doi:10.1038/labinvest.2010.180; published online 18 October 2010

KEYWORDS: barrier dysfunction; c-Jun kinase; leaky region; necrosis; tight junction; Yersinia enterocolitica

Yersinia enterocolitica is a gram-negative, enteropathogenic bacterium causing acute gastroenteritis, pseudoappendicitis and mesenteric lymphadenitis. Depending on age and immune status of the host, systemic manifestations, including reactive arthritis, erythema nodosum, uveitis and septicaemia can be further complications of the infection. ${ }^{1,2}$ $Y$. enterocolitica is a typical foodborne pathogen, which is primarily found in ground pork or refrigerated food, because of its ability to multiply at temperatures close to $0^{\circ} \mathrm{C}$. Transmission occurs mainly through the fecal-oral route.

Y. enterocolitica is known to express different sets of temperature-dependent virulence factors. A general infection model displays that ingested $Y$. enterocolitica, grown below $30^{\circ} \mathrm{C}$ are motile and express the outer membrane protein invasin, which binds with high affinity to $\beta 1$-integrins exposed on M-cells located between the enterocytes. Invasin has an important role for internalization of yersiniae. $Y$. enterocolitica is internalized by 'zipper-like mechanisms', passes the M-cell and reaches the Peyer's patches, in which it is able to proliferate and produce plasmid-encoded virulence factors. At $37^{\circ} \mathrm{C}$ body temperature Y. enterocolitica is not motile and expresses a type-III-secretion system, as well as $Y$. enterocolitica outer proteins (Yops), from its virulence plasmid (pYV). By translocating the Yop-effector proteins by the type-III-secretion system into the cytosol of the host cell Y. enterocolitica is assumed to suppress immune response (for review see Grassl et $a l^{3}$ ). The role of an enterotoxin that is exclusively produced below $30^{\circ} \mathrm{C}$ in vitro is not clear so far,

\footnotetext{
Department of Gastroenterology, Infectious Diseases and Rheumatology, Charité Campus Benjamin Franklin, Berlin, Germany; ${ }^{2}$ Department of General Medicine, Charité, Campus Benjamin Franklin, Berlin, Germany; ${ }^{3}$ Institute of Clinical Physiology, Charité, Campus Benjamin Franklin, Berlin, Germany and ${ }^{4}$ Institute of Medical Microbiology and Hygiene, University of Tübingen, Tübingen, Germany

Correspondence: Professor Dr JD Schulzke, MD, Department of Gastroenterology, Infectious Diseases and Rheumatology, Charité, Campus Benjamin Franklin, Hindenburgdamm 30, Berlin 12203, Germany.

E-mail: joerg.schulzke@charite.de

Received 4 March 2010; revised 23 August 2010; accepted 8 September 2010
} 
but most data argue against a prominent role of a secretory response by c-GMP from this toxin in vivo. ${ }^{4,5}$ However, although $Y$. enterocolitica is a well-studied organism, only little is known about the underlying mechanisms by which this pathogen causes barrier dysfunction leading to diarrhea and possible antigen uptake. The impact of acute $Y$. enterocolitica infection on intestinal barrier function was studied by our group in a mouse model in the past. Infection of mice with $Y$. enterocolitica $\mathrm{O} 8$ resulted in a decrease of epithelial resistance as measured by impedance spectroscopy, but showed unaltered $\mathrm{Na}^{+}$-glucose co-transport or electrogenic $\mathrm{Cl}^{-}$secretion. ${ }^{6}$

During the last two decades several enteric pathogens were described to disturb the intestinal barrier in different ways, including induction of local cell damage, eg by apoptosis, necrosis or focal leaks, ${ }^{7-9}$ stimulation of fluid and electrolyte secretion, activation of inflammatory cascades, as well as disruption of the tight junction (TJ) of epithelial cells. ${ }^{10}$

TJs are known as key determinants of barrier function. ${ }^{11,12}$ Localized between adjacent epithelial cells they limit the paracellular diffusion and regulate barrier function in response to different physiological requirements and stimuli. ${ }^{13,14}$ TJs are composed of four different types of transmembranal proteins, namely occluding, ${ }^{15}$ claudins, ${ }^{16}$ junctional adhesion molecules $^{17}$ and tricellulin. ${ }^{18}$ These proteins interact with each other, as well as with the actin cytoskeleton and membrane associated cytosolic proteins (ZO-1, -2 and -3 ), performing the structural organisation of the junctional complex and enabling regulatory inputs. ${ }^{19-21}$ In particular claudins, representing the major family of TJ proteins, are known to comprise sealing, but in part also pore-forming properties. ${ }^{22}$ Disruption of TJ integrity can cause severe barrier dysfunctions as known from eg Vibrio cholerae zonula occludens $\operatorname{toxin}^{23}$ or Clostridium perfringens enterotoxin. ${ }^{24}$

In the present study, we aimed to characterize barrier dysfunction induced by $Y$. enterocolitica in a cell culture model, in order to reveal diarrheal and barrier disturbing mechanisms.

\section{MATERIALS AND METHODS Cell Culture}

The cell line HT-29/B6, a subclone of the human colon carcinoma cell line HT-29, is an appropriate model to study barrier function, reflected by $\left(\mathrm{R}^{\mathrm{t}}\right) .{ }^{25}$ Culture medium
Roswell Memorial Park Institute (RPMI) 1640 (PAA Laboratories $\mathrm{GmbH}$, Pasching, Austria), contained 10\% fetal calf serum and $1 \%$ penicillin/streptomycin. Cells were incubated at $37^{\circ} \mathrm{C}$ in an air atmosphere containing $5 \% \mathrm{CO}_{2}$. For electrophysiological measurements HT-29/B6 cells were seeded on Millicell PCF filters (effective area $0.6 \mathrm{~cm}^{2} ; 3 \mu \mathrm{m}$ pores, Millicell PCF, Millipore, Schwalbach, Germany) and experiments were performed on confluent monolayers, giving transepithelial resistances $\left(\mathrm{R}^{\mathrm{t}}\right)$ of at least $350 \Omega \mathrm{cm}^{2}$.

\section{Bacterial Growth Conditions And Infection}

Bacterial strains used in this study are listed in Table 1. $Y$. enterocolitica wild-type bacteria were grown in LuriaBertani Broth (MP Biomedicals, Illkirch, France) at $27^{\circ} \mathrm{C}$ over night. Bacterial mutant strains were cultured in presence of $10 \mu \mathrm{g} / \mathrm{ml}$ nalidixin acid or $25 \mu \mathrm{g} / \mathrm{ml}$ kanamycin.

For infection, a 1:8 dilution of the bacterial over-night culture was incubated for additional $2 \mathrm{~h}$ at $27^{\circ} \mathrm{C}$. Bacteria were harvested from log-phase cultures, washed and re-suspended in RPMI. For preparation of bacterial culture supernatant or lysate bacteria were grown in RPMI medium. Culture supernatant was filtrated using $0.2 \mu \mathrm{m}$ ME DynaGard Syringe Tip Filter (Spectrum Laboratories, Rancho Dominguez, CA, USA) and concentrated using Amicon Ultra-15 centrifugal filter units (Millipore), bacterial lysate was produced from $250 \mathrm{ml}$ culture by means of a hydraulic press (FRENCHPress, Thermo Spectronic, Cambridge, UK).

Before infection confluent monolayers of HT-29/B6 cells were shifted to serum- and antibiotic-free RPMI medium. Cells were infected with $10^{8}$ or $10^{7}$ bacteria from the apical side equalling a multiplicity of infection (MOI) of 100 or 10 . Incubation was carried out at $37^{\circ} \mathrm{C}$ in an atmosphere of $95 \% \mathrm{O}_{2}$ and $5 \% \mathrm{CO}_{2} .2 .5 \mathrm{~h}$ post infection (p.i.) $100 \mu \mathrm{g} / \mathrm{ml}$ gentamicin was added.

In parallel to infection with $Y$. enterocolitica strains, four types of controls were performed: (i) without adding bacteria, (ii) with addition of heat-inactivated bacteria (carried out at $95^{\circ} \mathrm{C}$ or $56^{\circ} \mathrm{C}$ for $15 \mathrm{~min}$ ), (iii) lysates or supernatants and (iv) infection with E. coli K12.

\section{Measurement of Transepithelial Resistance}

Transepithelial resistance $\left(\mathrm{R}^{\mathrm{t}}, \Omega \mathrm{cm}^{2}\right)$ was determined with an ohmmeter (D Sorgenfrei, Institute of Clinical Physiology,

Table 1 Bacterial strains

\begin{tabular}{|c|c|c|}
\hline Strain & Description & Reference or source \\
\hline Ye O9 & Y. enterocolitica serotype O9; clinical isolate & provided by $\mathrm{R}$ Ignatius \\
\hline WA-C & Virulence plasmid cured derivative of WA-P, $\mathrm{Nal}^{\mathrm{R}}$ & Heesemann and Laufs, $1983^{26}$ \\
\hline WA-P inv ${ }^{-}$ & WA-P $\Delta i n v, \mathrm{Nal}^{\mathrm{R}}$ & Ruckdeschel et al, $1996^{27}$ \\
\hline
\end{tabular}


Berlin, Germany) under sterile conditions at $37^{\circ} \mathrm{C}$. Data were corrected for the resistance of the empty filter.

\section{Flux Measurement}

$48 \mathrm{~h}$ after infection, HT-29/B6 cell monolayers were mounted into Ussing-type chambers. $\mathrm{R}^{\mathrm{t}}$ was determined by a computerized automatic clamp device (Fiebig Hard- \& Software, Berlin, Germany) and unidirectional flux-measurements were performed from mucosal to serosal under shortcircuit conditions with $\left[{ }^{3} \mathrm{H}\right]$-mannitol (Biotrend, Cologne, Germany), fluorescein and fluorescein isothiocyanatelabelled dextran 4000 (Sigma-Aldrich, Schnelldorf, Germany) according to previous protocols. ${ }^{28}$

Labeled dyes were added to the mucosal side and samples were taken from the basolateral chamber at specific intervals. Fluorescence was measured in a spectrofluorimeter (SpectraMaxGemini, Molecular Devices, Sunnyvale, CA, USA), $\left[{ }^{3} \mathrm{H}\right]$-mannitol was analysed in a Tri-Carb 2100TR liquid scintillation counter (Packard, Frankfurt, Germany) using Ultima Gold high flash-point liquid scintillation cocktail (PerkinElmer LAS GmbH, Rodgau-Jügesheim, Germany). Permeability was calculated from flux over concentration difference.

\section{Electrogenic Chloride Secretion}

Chloride secretion was examined in Ussing-type chambers by the addition of $10^{-5} \mathrm{M}$ of the blocker bumetanide or $10^{-5} \mathrm{M}$ of the inductor forskolin (Sigma-Aldrich) to the basolateral chamber and by quantifying the resulting changes in short circuit current $\left(\mathrm{I}_{\mathrm{SC}}\right)$.

\section{Measurement of Calcium Response}

Intracellular calcium measurements were carried out as described previously ${ }^{29}$ using the $\mathrm{Ca}^{2+}$-sensitive dye fura-2AM based on methods described by Grynkiewicz et al. ${ }^{30}$ Briefly, before each experiment HT-29/B6 cultured on coverslips were incubated with $2 \times 10^{-5} \mathrm{M}$ fura-2AM (Sigma-Aldrich) in HEPES-Ringer's solution (in mM: $151 \mathrm{Na}^{+}, 5 \mathrm{~K}^{+}, 1.7$ $\mathrm{Ca}^{2+}, 0.9 \mathrm{Mg}^{2+}, 156.7 \mathrm{Cl}^{-}, 0.9 \mathrm{SO}_{4}^{2-}, 1 \mathrm{H}_{2} \mathrm{PO}_{4}^{-}, 10$ HEPES and 5 glucose) for $30 \mathrm{~min}$ at $37^{\circ} \mathrm{C}$. Then the coverslip was placed into a perfusion chamber. After extracellular dyes were washed out HT-29/B6 monolayers were perfused with HEPES-Ringer's solution containing vital or heat-inactivated $Y$. enterocolitica $\left(10^{8}\right.$ per $\left.\mathrm{ml}\right)$ up to $1 \mathrm{~h}$. Measurements were performed at $37^{\circ} \mathrm{C}$ or room temperature. The excitation light was generated by a xenon lamp (Osram XPO 75 W/2) filtered by two rotating filters ( 6 per s) at 340 and $380 \mathrm{~nm}$. The resulting fluorescence of fura-2AM was detected at $510 \mathrm{~nm}$ by a photomultiplier (Hamamatsu $928 \mathrm{SF}$ ) with consequent signal detection with an EPC-9 patch-clamp amplifier. Changes in the $340 / 380 \mathrm{~nm}$ fluorescence ratio represented changes of intracellular calcium level. Calcium mobilization from intracellular stores was stimulated by application of $300 \mu \mathrm{M}$ ATP (Sigma-Aldrich).
The influence of calcium-chelation on $\mathrm{R}^{\mathrm{t}}$ after infection with $Y$. enterocolitica was measured after application of membrane permeable BAPTA-AM (Calbiochem, Darmstadt, Germany) to the basolateral compartment. Confluent monolayers were shifted to RPMI medium and treated with $10^{-5}$-M BAPTA-AM $1 \mathrm{~h}$ before infection. Infection procedure was carried out as described above. The $5 \mathrm{~h}$ p.i. BAPTA-AM was removed by basolateral medium exchange. $\mathrm{R}^{\mathrm{t}}$ was measured $48 \mathrm{~h}$.

\section{Two-Path Impedance Spectroscopy}

Epithelial resistance $\left(\mathrm{R}^{\mathrm{epi}}\right)$, transcellular resistance $\left(\mathrm{R}^{\text {trans }}\right)$ and paracellular resistance $\left(\mathrm{R}^{\text {para }}\right)$ of HT-29/B6 monolayers were measured by two-path impedance spectroscopy as published recently. ${ }^{31}$ Briefly, filters were mounted in Ussingtype impedance chambers and bathed with Ringer's solution. Sinusoidal currents in frequencies from 1 to $65 \mathrm{kHz}$ were provided by a programmable frequency response analyzer (402, Beran Instruments, Devon, UK) in combination with an electrochemical interface (1286, Solartron Schlumberger, Farnborough, UK). Additionally, fluxes of the paracellular marker, fluorescein were measured. Change of $\mathrm{R}^{\text {para }}$ was forced by $\mathrm{Ca}^{2+}$ removal using ethylene glycol tetraacetic acid (EGTA) and the resulting impedance spectra and fluxes before and after chelating extracellular $\mathrm{Ca}^{2+}$ were used for calculation.

\section{Conductance Scanning}

To examine the spatial distribution of conductivity conductance scanning was performed. Briefly, the cell monolayer was placed horizontally in a chamber between two electrodes. Although an electric current passed through the monolayer, the resulting electric field was detected on the apical side of the cell layer with a pair of microelectrodes. The tissue conductivity could be calculated from the potential difference between these two electrodes. Local changes were detected by an increase from basic conductivity when scanning parallel to the surface of the cell layer. For detailed description see Troeger et $a l^{9}$ and Gitter et al. ${ }^{32}$

\section{Lactate dehydrogenase (LDH) Release Assay}

As an indicator of cell disruption the LDH release from the cells was measured according to Madara and Stafford. ${ }^{33}$ The LDH content was measured in apical supernatants and in whole residual cells after detergent extraction with $2 \%$ Triton X-100 for $20 \mathrm{~min}$. The total LDH content of residual cells was set as $100 \%$ and LDH released into supernatants was calculated.

\section{TUNEL-Staining for Apoptosis}

Cells were removed from filter supports with $0.5 \%$. TrypsinEDTA (Invitrogen, Karlsruhe, Germany) at $37^{\circ} \mathrm{C}$. RPMI medium containing $10 \%$ fetal calf serum and $1 \%$ penicillin/ streptomycin was added and cells were separated with a pipette tip. Cell suspensions were washed three times with phosphate-buffered saline (PBS) and cellular DNA was 
stained with terminal deoxynucleotidyl transferase-mediated deoxyuridine triphosphate nick-end labelling (TUNEL, In situ Cell Death Detection Kit, Fluorescein, Roche, Mannheim, Germany) according to the manufacturer's protocol. Samples were analysed by fluorescence activated cell sorting (FACSCalibur, BD Biosciences, Heidelberg, Germany). The apoptotic ratio was calculated as percentage of TUNELpositive cells within total cells. As positive control apoptosis was induced with a combination of $500 \mathrm{U} / \mathrm{ml}$ tumor necrosis factor $\alpha$ (TEBU, Offenbach, Germany) and $10 \mathrm{ng} / \mathrm{ml}$ interleukin-13 (R\&D systems, Wiesbaden, Germany) in HT-29/B6. ${ }^{34}$ Both cytokines were added to the basolateral compartment and incubation was carried out at $37^{\circ} \mathrm{C}$ for $48 \mathrm{~h}$.

\section{Western Blot}

For protein expression analysis the western blot technique was applied as described previously. ${ }^{35}$ Whole cell extracts were generated with ice-cold lysis buffer, including $10 \mathrm{mM}$ Tris, pH 7.5, $150 \mathrm{mM} \mathrm{NaCl}, 0.5 \%$ Triton X-100, 0.1\% SDS and complete protease inhibitor mixture (Roche). After incubation for $30-60 \mathrm{~min}$ on ice, insoluble material was removed by centrifugation at $15000 \mathrm{~g}$ for $15 \mathrm{~min}$ at $4^{\circ} \mathrm{C}$. Protein concentrations were determined by Pierce BCA assay and $20-30 \mu \mathrm{g}$ of whole cell extracts were loaded on polyacrylamide gels. For immunodetection the following antibodies were used: anti-occludin and anti ZO-1 (1:2000, Zymed, San Francisco, CA, USA), anti-tricellulin (customized by the group of $\mathrm{O}$ Huber, Institute of Clinical Chemistry and Pathobiochemistry, Charité, Germany) anticlaudin- 1 to $-5,-8$ and -10 (1:1000, Zymed), MAPK Family Antibody Sampler Kit and Phospho-MAPK Family Antibody Sampler Kit (Cell Signaling Technology, Danvers, MA, USA), as well as anti- $\beta$-actin (1:5000, Sigma-Aldrich) as internal loading control. Densitometric quantification was carried out with AIDA quantification software (Raytest, Straubenhardt, Germany), values were normalized to $\beta$-actin.

\section{Biotinylation Assay}

Visualization of 'leaky regions' in HT-29/B6 monolayers was performed $48 \mathrm{~h}$ p.i. using Sulfo-NHS-SS-Biotin, an aminereactive biotinylation reagent, which binds to freely accessible primary amino groups of proteins. On tight monolayers only proteins exposed at the apical cell surface are accessible for the apically added 606 Dalton Sulfo-NHS-biotin. In contrast, barrier defects enable the reagent to gain access also to the basolateral space. Subsequent labelling of bound biotin using a fluorescence-labelled streptavidin can visualize loci of increased macromolecule passage.

Biotinylation combined with immunostaining of $\mathrm{TJ}$ proteins and subsequent analyses by confocal scanning microscopy was carried out as follows. Medium was removed and monolayers resting on filter supports were washed and placed in PBS containing calcium and magnesium (PBS, PAA Laboratories $\mathrm{GmbH}$ ). In order to exclude internalization of biotin, HT-29/B6 monolayers were cooled to $4^{\circ} \mathrm{C}$, before
$1 \mathrm{mg} / \mathrm{ml}$ Sulfo-NHS-SS-Biotin (Cell Surface Protein Isolation Kit, Thermo Fisher Scientific, Bonn, Germany) was added to the apical side. Binding was allowed for $30 \mathrm{~min}$ at $4^{\circ} \mathrm{C}$. Afterwards Sulfo-NHS-SS-biotin was removed and residual amine-reactivity was quenched by washing with ice cold $100 \mathrm{mM}$ glycin, followed by two further washing steps with TRIS-buffered saline and PBS. Fixation was carried out with $2 \%$ paraformaldehyde at room temperature for $30 \mathrm{~min}$. Cells were permeabilized with $0.05 \%$ Triton X-100 diluted in PBS and TJ proteins were immunostained with TJ-antibodies (claudins 1:100, ZO-1 and occludin 1:200, Zymed) followed by incubation with Alexa Fluor 488 goat anti-mouse IgG or Alexa Fluor 488 goat anti-rabbit $\operatorname{IgG}$ (1:500, Invitrogen) and Alexa Fluor 594 conjugated streptavidin (1:100, Invitrogen). Biotinylation and changes in the TJ meshwork were visualized by confocal laser-scanning microscopy (Zeiss LSM 510META, Jena, Germany), using excitation wavelength of $543 \mathrm{~nm}$ for streptavidin-biotin and $488 \mathrm{~nm}$ for TJ proteins.

\section{Freeze Fracture Electron Microscopy}

Freeze fracture electron microscopy analysis was carried out as described previously ${ }^{36}$ and is described in detail in the supplement.

\section{Quantitative Real-Time PCR (qRT-PCR)}

Total RNA was extracted from HT-29/B6 cells by Trizol (Invitrogen) following the manufacturer's protocol. For RTPCR High-Capacity cDNA Archive Kit (Applied Biosystems, Mannheim, Germany) was used. RT-PCR was carried out using TaqMan Gene Expression Assay no Hs00273282_s1 for human claudin-8, Hs00265816_s1 for claudin-3 and Hs00268480_m1 for ZO-1. Human glyceraldehyde 3-phosphate dehydrogenase (GAPDH, Applied Biosystems) served as endogenous control. Claudin-8- and GAPDH-cDNA were quantified by VIC and FAM reporter dyes covalently attached to the $5^{\prime}$-terminal base of the probes. PCR was set up in duplicates, and threshold cycle values of the target genes were normalized to the endogenous control. Differential expression was calculated according to the $2^{-\Delta \Delta C T}$ method.

\section{Inhibition of Signaling Pathways}

Confluent monolayers were shifted to RPMI medium containing $2 \%$ fetal calf serum. Around $2 \mathrm{~h}$ before infection cells were treated with $10 \mu \mathrm{M} \mathrm{c}$-Jun-terminal kinase inhibitor SP600125 (Sigma-Aldrich) or equal amounts of DMSO as control from both sides. Alternatively, $2.5 \mu \mathrm{M}$ JNKi-1 (Enzo life Sciences, Loerrach, Germany) was applied. Infection procedure and measurement of $\mathrm{R}^{\mathrm{t}}$ were carried out as described above. For all other inhibitors tested in this study please see Supplementary Table 1.

\section{Statistics}

All data are expressed as means \pm s.e. of the mean (s.e.m.). Statistical analysis was performed using Student's $t$-test, adjusted by Holm-Bonferroni correction for multiple 
comparisons. $P<0.05$ was considered significant $\left({ }^{\star} P<0.05\right.$, ${ }^{* *} P<0.01$ and $\left.{ }^{* *} P<0.001\right)$.

\section{RESULTS}

\section{Infection With $Y$. enterocolitica Results in a Decrease of Transepithelial Resistance}

Confluent monolayers of HT-29/B6 grown on permeable supports were infected with $10^{8}$ or $10^{7} \mathrm{Y}$. enterocolitica $\mathrm{O} 9$ from the apical side and were incubated at $37^{\circ} \mathrm{C}$. The bacteria were killed by addition of gentamicin $2.5 \mathrm{~h}$ p.i. Barrier integrity was monitored by measuring the $\mathrm{R}^{\mathrm{t}}$ over $48 \mathrm{~h}$ at $37^{\circ} \mathrm{C}$. In contrast to uninfected control monolayers, which exhibited only a slight decrease from initial resistance $(85 \pm 6 \% ; n=6), 10^{8} Y$. enterocolitica reduced $\mathrm{R}^{\mathrm{t}}$ to $40 \pm 6 \%$ of initial resistance $(P<0.01 ; n=6)$ at 48 h p.i. $10^{7}$ bacteria diminished $\mathrm{R}^{\mathrm{t}}$ to $60 \pm 8 \%(P<0.05 ; n=6)$ suggesting a dosedependence (Figure 1a). The E. coli K12 strain was tested as a bacterial negative control and did not reveal any significant differences compared with uninfected controls $(71 \pm 2 \%$ in K12-treated monolayers. vs $89 \pm 10 \%$ in controls; $n=4$ ).

\section{Characterization of Barrier Impairment}

All subsequent analyses were performed on monolayers infected with $10^{8}$ vital $Y$. enterocolitica O9 in parallel to untreated controls at $48 \mathrm{~h}$ p.i. To further analyze epithelial barrier function monolayers were mounted into modified Ussing-type chambers. $\mathrm{I}_{\mathrm{SC}}$ was examined and unidirectional flux measurements with uncharged molecules of different size were performed.

Basal $\mathrm{I}_{\mathrm{SC}}$ was not affected by $Y$. enterocolitica (Figure $1 \mathrm{~b}$ ). Moreover, changes of $\mathrm{I}_{\mathrm{SC}}$ did not significantly differ from controls when chloride secretion was stimulated: Forskolin induced an increase in $\mathrm{I}_{\mathrm{SC}}$ of about $5.3 \pm 0.2$-fold in controls and $6.4 \pm 0.6$-fold in infected monolayers $(n=3)$. Inhibition of chloride secretion by bumetanide reduced $\mathrm{I}_{\mathrm{SC}}$ about $1.3 \pm 0.04$-fold in controls and $1.2 \pm 0.05$-fold in $Y$. enterocolitica-treated cells.

In contrast, permeability for mannitol (182 Da, Stokesradius $3.6 \AA$ ) was increased 2.2 -fold, namely from $2.3 \pm 0.2$ in control to $5.3 \pm 0.3 \times 10^{-6} \mathrm{~cm} / \mathrm{s}$ in $Y$. enterocolitica-treated monolayers $(P<0.0001 ; n=6)$. A 6 -fold permeability increase was measured for fluorescein (332 Da, $4.5 \AA$ ).
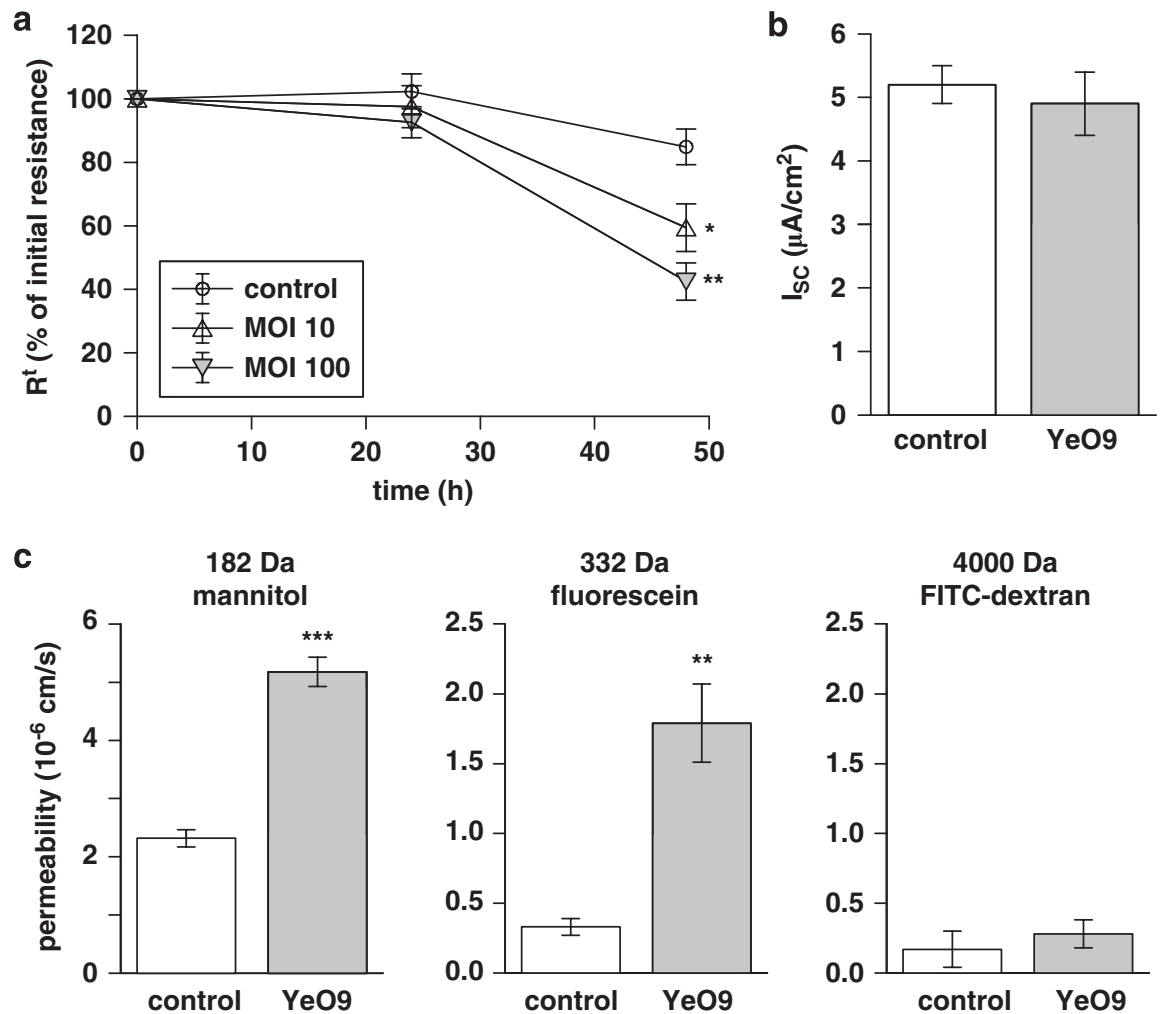

Figure 1 Characterization of barrier impairment. (a) HT-29/B6 monolayers were apically infected with $10^{7}$ (multiplicity of infection (MOI) 10 ) or $10^{8}$ $Y$. enterocolitica $\mathrm{O} 9(\mathrm{MOI} 100)$ and incubated at $37^{\circ} \mathrm{C} .2 .5 \mathrm{~h}$ p.i. bacteria were killed by the addition of $100 \mu \mathrm{g} / \mathrm{ml}$ gentamycin. $\mathrm{R}^{\mathrm{t}}$ was monitored over $48 \mathrm{~h}$ and was dose and time dependent $\left(n=6,{ }^{*} P<0.05,{ }^{*} P<0.01\right.$ vs control). (b) No changes in Isc were obtained $(n=18)$. (c) Permeability of infected and control monolayers was determined by flux measurement in modified Ussing-type chambers. Y. enterocolitica increased permeability for 182 Da mannitol ( $n=6$, ${ }^{* * *} P<0.001$ vs control) and of 332 Da fluorescein $\left(n=6,{ }^{* *} p<0.01\right.$ vs control). For 4000 Da fluorescein isothiocyanate-Dextran layers from both conditions were almost impermeable. 
The permeability was enhanced from $0.33 \pm 0.1$ in control to $1.79 \pm 0.3 \times 10^{-6} \mathrm{~cm} / \mathrm{s}$ in infected monolayers $(P<0.01$; $n=6$ ). However, when macromolecule permeation of $4 \mathrm{kDa}$ fluorescein isothiocyanate-dextran $(\sim 13 \AA)$ was examined, no significant changes were observed between controls $\left(0.17 \pm 0.1 \times 10^{-6} \mathrm{~cm} / \mathrm{s} ; n=6\right)$ and $Y$. enterocolitica-infected cells $\left(0.28 \pm 0.1 \times 10^{-6} \mathrm{~cm} / \mathrm{s} ; n=6\right)$ (Figure 1c).

\section{Identification of Barrier Defect}

The conductance scanning-technique was applied to elucidate whether increased conductance occurred homogeneously

a

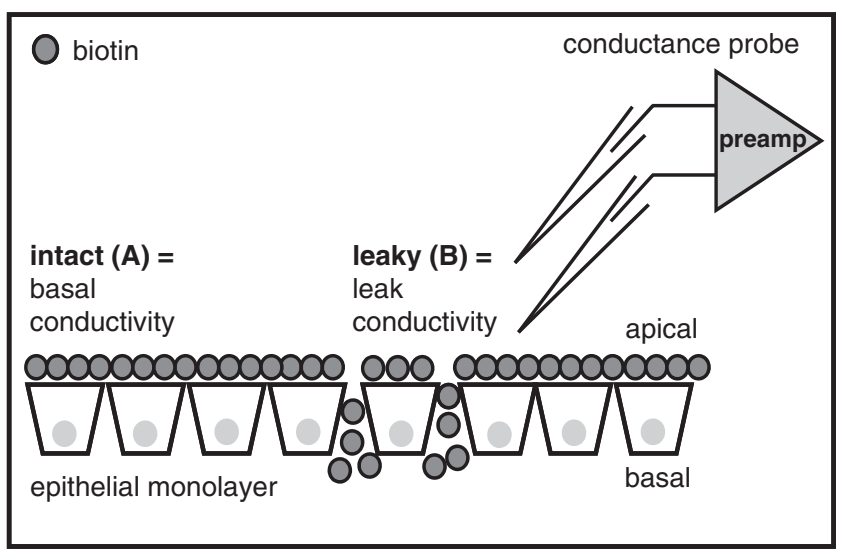

d

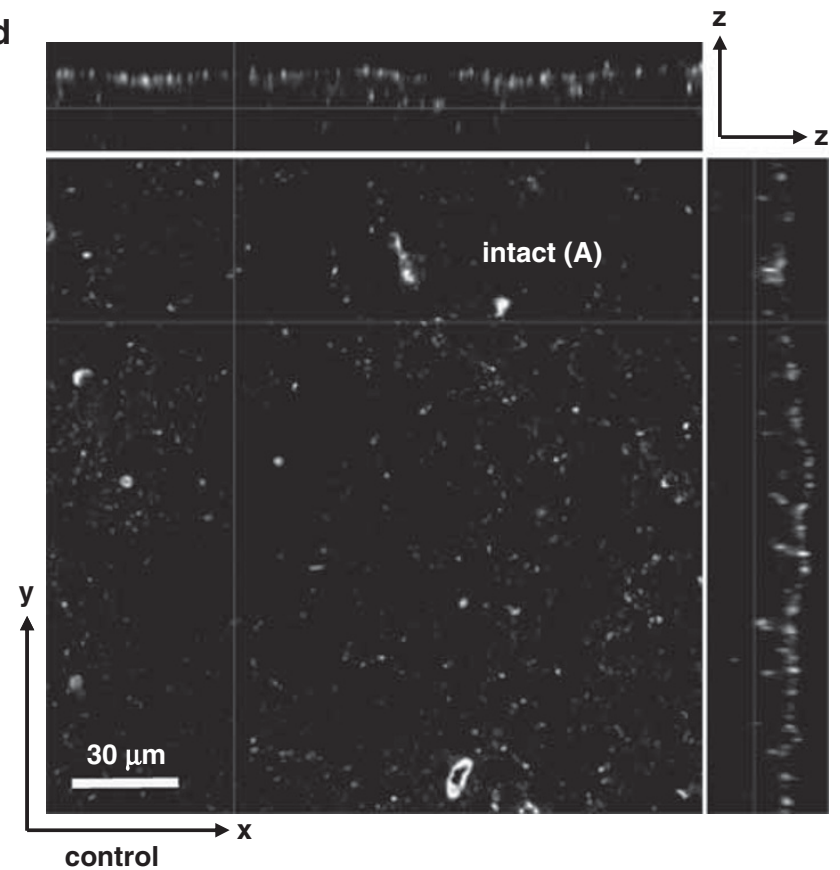

distributed over the monolayer or represents a local phenomenon. In Figure 2a, the experimental ideas of conductance scanning and of biotin permeation across a leaky region' is depicted schematically. On each monolayer an area of $1 \mathrm{~mm}^{2}$ was scanned in steps of $100 \mu \mathrm{m}$. As shown in Figure $2 \mathrm{~b}$, basal conductivity was unchanged in infected and control monolayers $\left(2.5 \pm 0.8 \mathrm{mS} / \mathrm{cm}^{2}\right.$ after $Y$. enterocolitica infection vs $2.2 \pm 0.6 \mathrm{mS} / \mathrm{cm}^{2}$ in controls; $n=7$ ) and was assumed to reflect intact regions of the monolayer. On top of this basal conductivity, local increases in conductance were observed $\left(\mathrm{G}_{\text {leak}}, \mu \mathrm{S}\right)$. As described previously, ${ }^{37}$ such slight
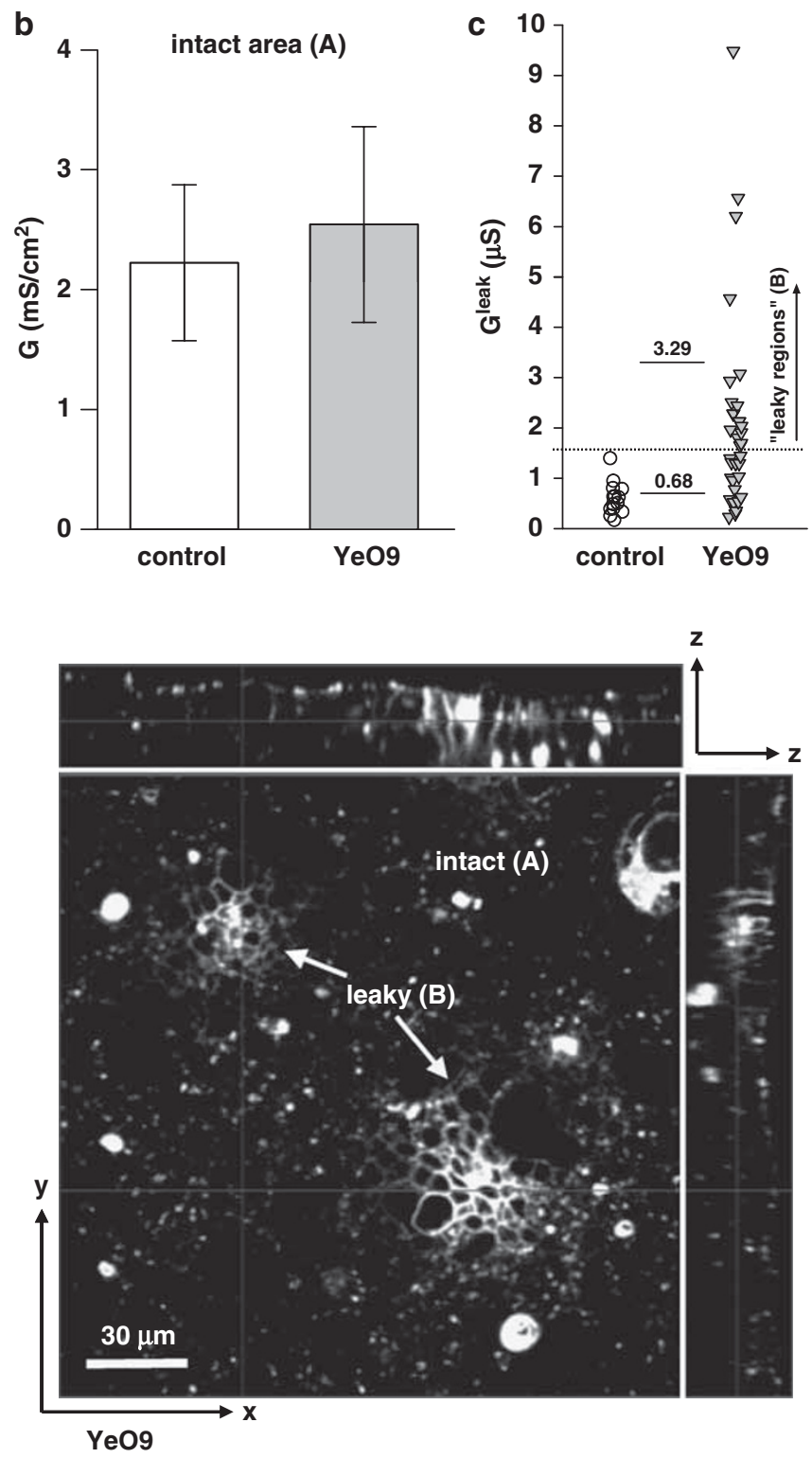

Figure 2 Patchy distribution of barrier defects. (a) Cartoon illustrating both, conductance scanning and biotin permeation, in intact (A) and leaky (B) regions. For details see text. (b) Conductance scanning for regional resistance distribution was performed on infected and control monolayers. Basal conductivity of intact regions in infected monolayers was comparable to controls. Data are means \pm s.e.m. of $n=7$. (c) HT-29/B6 monolayers were scanned for sites exhibiting locally elevated conductances (controls and infected monolayers $n=7$ each). A dotted line was set to indicate a safe upper limit of local conductance peaks caused by apoptosis. Values above that line are regarded as 'leaky regions'. Horizontal lines indicate means of the respective group. (d) A patchy distribution of 'leaky regions' was visualized by biotinylation assay (Z-axis stack) and subsequent confocal laser scanning microscopy. 'Intact regions' are marked as (A) and 'leaky regions' as (B). 
increases from basal conductivity were associated with apoptotic rosettes characterized by the enlargement of adjacent cells visible in both controls and infected monolayers. As all leaks detected in controls were corresponding to apoptotic events, an extrapolation line was drawn in safe distance above these values (1.6 $\mu \mathrm{S}$, Figure $2 \mathrm{c}$ ).

Apoptosis-assigned leaks exhibited a leak conductance of $0.68 \pm 0.07 \mu \mathrm{S}$ (controls: 14 leaks and infected: 15 leaks). However, in Y. enterocolitica-treated monolayers additional regions of elevated leakiness were detected above the upper limit for apoptotic leaks (dotted line, Figure 2c) and assigned as 'leaky regions'. This 'leaky region'-assigned leak conductance was $3.29 \pm 0.56 \mu \mathrm{S}$ (16 leaks) and thus five-fold higher than that caused by apoptosis.

Mean $\mathrm{R}^{\mathrm{t}}$ of all control monolayers amounted to $546 \pm 33 \Omega \times \mathrm{cm}^{2}$ equivalent to a conductivity of $1.9 \pm$ $0.1 \mathrm{mS} / \mathrm{cm}^{2}\left(\mathrm{G}_{\text {con }}\right)$. Infected layers had a mean total conductance of $3.5 \pm 0.3 \mathrm{mS} / \mathrm{cm}^{2}$ ( $\left.\mathrm{G}_{\mathrm{Ye}} ; P<0.001 ; n=7\right)$. Thus, $\mathrm{G}_{\text {con }}$ and $\mathrm{G}_{\mathrm{Ye}}$ differed by $1.6 \mathrm{mS} / \mathrm{cm}^{2}(\mathrm{G} \Delta)$. From $\mathrm{G} \Delta$ and $\mathrm{G}_{\text {leak }}$ a number of about 300 'leaky regions' $/ \mathrm{cm}^{2}$ was estimated (contributing to $46 \%$ of $\mathrm{G}_{\mathrm{Ye}}$ ).

Subsequently, it was possible to visualize highly permeable regions by means of a biotinylation assay. A Sulfo-NHSbiotin that binds to primary amino groups of accessible proteins was apically added to monolayers. After locating bound biotin with fluorescence-labelled streptavidin it became obvious that the intact HT-29/B6 monolayer did not permit passage of biotin to the basolateral space at all, since only the apical surface was labelled in controls (Figure 2d). In contrast, $Y$. enterocolitica-infected monolayers exhibited focal areas of intensive staining of cell boundaries (marked with $B$ in Figure 2d). These sites did not represent visible leaks but were identified as 'leaky regions', in which biotin could permeate from the apical side towards the basolateral compartment. These 'leaky regions' appeared in different size and randomly distributed over infected monolayers. Surrounding areas were not leaky and showed biotinylation only on the surface in accordance to controls (marked with A in Figure 2d).

\section{Paracellular Leakiness and Impaired TJs}

Discrimination between paracellular and transcellular resistance was achieved by two-path impedance spectroscopy. The infection of HT-29/B6 resulted in an 8.5-fold reduction of $\mathrm{R}^{\text {para }}$ to $354 \pm 100$ compared with $3012 \pm 496 \Omega \times \mathrm{cm}^{2}$ in controls $(P<0.01 ; n=6)$. $\mathrm{R}^{\text {epi }}$ reflecting the total resistance of the monolayer was 3.8 -fold reduced to $184 \pm 16 \Omega \times \mathrm{cm}^{2}$, whereas uninfected monolayers showed $704 \pm 21 \Omega \times \mathrm{cm}^{2}$ $(P<0.001 ; n=6)$. Transcellular resistance was not significantly changed (1147 \pm 477 in infected vs $978 \pm 181 \Omega \times \mathrm{cm}^{2}$ in control monolayers; $n=6$ ) (Figure $3 \mathrm{a}$ ).

To further elucidate the paracellular leakiness, changes of TJ proteins were investigated. Claudin- $1,-2,-3,-4,-5,-8$ and -10 , as well as ZO-1, occludin and tricellulin were quantified by immunoblotting. Levels of claudin-2, $-3,-8$ and -10 were reduced to $58 \pm 11 \%(P<0.01 ; n=6), 84 \pm 7 \% \quad(P<0.05$; $n=6), 63 \pm 7 \%(P<0.01 ; n=6)$ and $70 \pm 4 \%(P<0.01$; $n=6)$, respectively. $\mathrm{ZO}-1$ was reduced to $52 \pm 4 \%$ $(P<0.01 ; n=6)$, expression of occludin tricellulin, claudin-1, -4 and -5 was unchanged $(n=6)$ (Figures $3 \mathrm{~b}$ and $c)$.

Localization of TJ proteins was characterized by confocal laser scanning microscopy. This was done in combination with the biotinylation assay for identification of 'leaky regions' (Figure 4). Compared with confocal slicing (approximately $0.5 \mu \mathrm{m}$ ) the height of the cells throughout the epithelial layer varies considerably. Therefore, the entire TJ meshwork staining was visualized in imaged fields by maximum projecting $z$-stacks on the $x y$-plane. In infected monolayers, intact regions exhibiting no biotin passage showed the typical TJ meshwork for ZO-1, occluding, as well as claudin-3, -4, -5 and -8 comparable to controls. In 'leaky regions' labelled by biotin-passage, no change in ZO-1 (Figure 4a), occludin or claudin-5 was observed (data not shown). In contrast, the claudin- $3,-4$ and -8 patterns differed in 'leaky regions' from that of surrounding intact regions and from controls. Claudin-4 (Figure 4b) and also claudin-3 (not shown) were re-distributed as indicated by a loss of the meshwork structure of the staining pattern and an enhanced intracellular signal. However, changes in claudin-8 staining were even more pronounced. Claudin- 8 appeared diffuse in 'leaky regions' showing no typical TJ pattern any more (Figure 4c). In addition, mRNA levels for claudin-8, claudin3 and ZO- 1 were examined by qRT-PCR. As early as $6 \mathrm{~h}$ after infection mRNA level of claudin-8 was reduced to $31 \pm 11 \%$ $(P<0.01 ; n=5)$, whereas the expression of ZO-1 mRNA was only slightly diminished to $79 \pm 4 \%(P<0.01 ; n=5)$. Level of claudin-3 mRNA remained unchanged $(n=5)$ (Figure 5).

\section{TJ Strands Analyzed by Freeze Fracture Electron Microscopy}

Because TJs of 'leaky regions' were lost or at least critically altered, to our experience such structures may not freezefracture as complete strands. Thus the identified TJ strands in infected cells may represent those of 'intact regions'. As a result, no significant changes were observed between controls and $Y$. enterocolitica infection regarding number of horizontally oriented strands, meshwork depth, density or occurrence of strand breaks $>20 \mathrm{~nm}$. All strands were of the "continuous type", none of a 'particle type' (Supplementary Figure S1 and Supplementary Table S1).

\section{Role of Prominent Virulence Factors}

In order to elucidate the virulence factor of $Y$. enterocolitica responsible for this barrier effect, the infection procedure was manipulated, seeking a crude classification of potential virulence determinates. As the expression of different Yersinia-virulence factors is temperature dependent, the bacteria were cultured at 27 or $37^{\circ} \mathrm{C}$ before infection. However, the decrease of $\mathrm{R}^{\mathrm{t}}$ in HT-29/B6 was independent of bacterial culture temperature (data not shown). Moreover, 

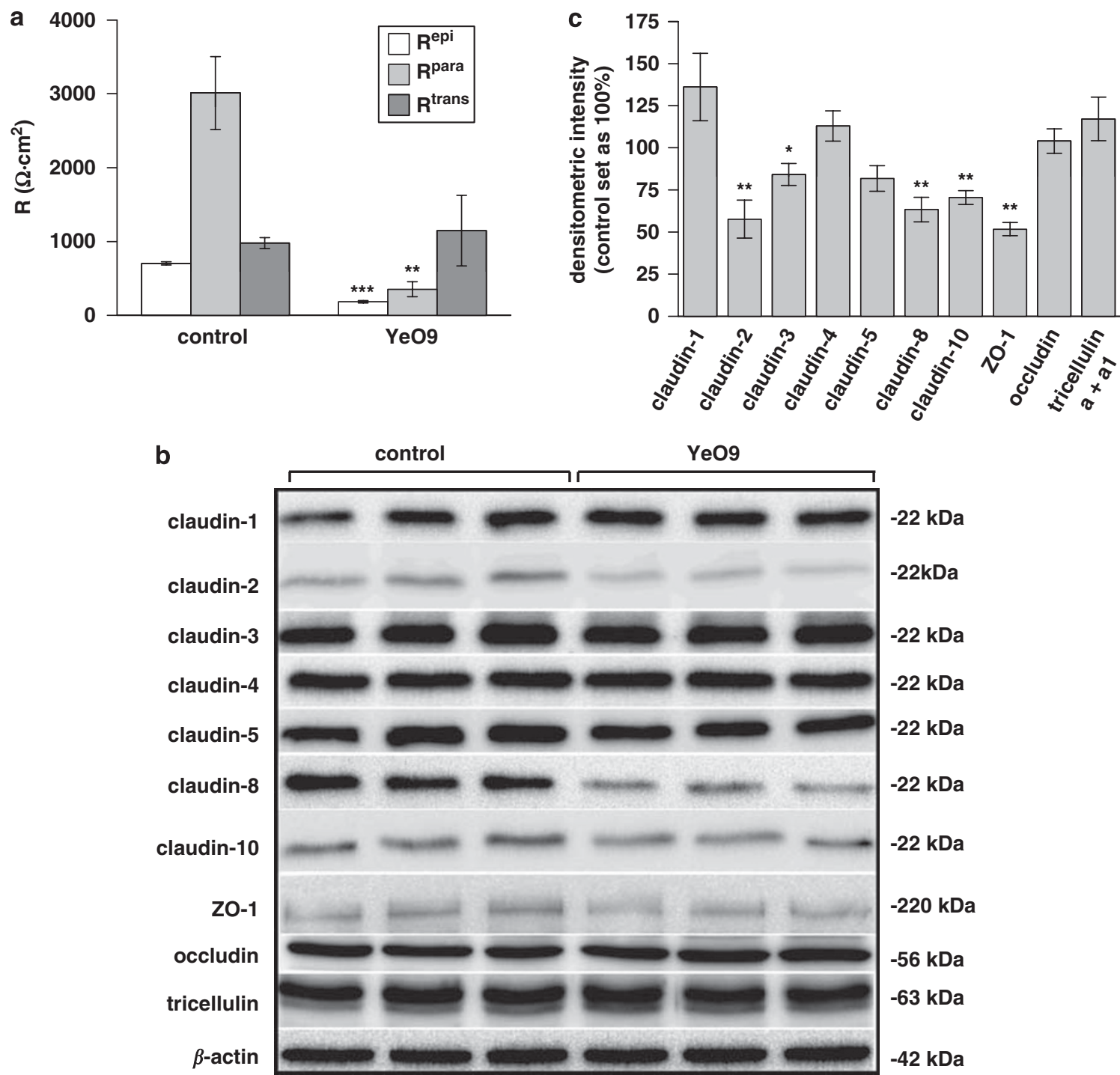

Figure 3 Paracellular leakiness and impaired tight junctions. (a) $R^{\text {epi }}, R^{\text {trans }}$ and $R^{\text {para }}$ were measured by two-path impedance spectroscopy. $R^{\text {epi }}$, reflecting the total epithelial resistance, as well as the paracellular resistance $R^{\text {para }}$ were reduced in $Y$. enterocolitica-infected HT-29/B6 monolayers. Data are presented as means \pm s.e.m. of $n=6\left({ }^{* * P}<0.01,{ }^{* * *} P<0.001\right.$ vs control). (b) Western blot analyses revealed reduced protein levels of claudin-2 ( $n=9$, $\left.{ }^{* * P}<0.01\right)$, claudin-3 $\left(n=9,{ }^{*} P<0.05\right)$, claudin-8 $\left(n=12,{ }^{* *} P<0.01\right)$ and claudin-10 $\left(n=6,{ }^{*} P<0.01\right)$, as well as of ZO-1 $\left(n=6,{ }^{* *} P<0.01\right)$ in infected HT-29/B6 monolayers compared with control. (c) Densitometric quantification of TJ proteins after normalization with $\beta$-actin $(n=6-12)$.

only vital bacteria were able to cause the effect, as neither heat treatment of yersiniae $\left(95\right.$ or $56^{\circ} \mathrm{C}$ ), nor Y. enterocolitica culture supernatants or bacterial lysates had any effect on $\mathrm{R}^{\mathrm{t}}$ (Supplementary Figure S2). Also, YeO9-conditioned media, produced by co-culturing of HT29/B6 and bacteria, had no significant effect on $\mathrm{R}^{\mathrm{t}}$ (data not shown) revealing the presence of the epithelial cells was not necessary to trigger production and/or secretion of a responsible $Y$. enterocolitica virulence factor.

When the whole experiment was conducted over $48 \mathrm{~h}$ at $27^{\circ} \mathrm{C}$, no $\mathrm{R}^{\mathrm{t}}$ decline occurred ( $88 \pm 13 \%$ after $Y$. enterocolitica infection $v s 93 \pm 15 \%$ in controls; $n=6$ each).

In a further approach, mutant-strains were tested for their effect on $\mathrm{R}^{\mathrm{t}}$. HT-29/B6 monolayers were infected with three different mutant-strains derived from the wild-type
WA-P (serotype O8): (i) WA-C cured of the pYV, (ii) WA-P inv ${ }^{-}$deficient for the chromosomal encoded invasion factor invasin and (iii) WA-C inv ${ }^{-}$lacking both $\mathrm{pYV}$ and invasin. The wild-type strain WA-P reduced $\mathrm{R}^{\mathrm{t}}$ to the same level as $Y$. enterocolitica O9. However, the infection of HT-29/B6 with each of the three mutant-strains resulted also in a significant drop of $\mathrm{R}^{\mathrm{t}}$ (Figure 6). Although uninfected controls stabilized at $87 \pm 3 \%(n=18)$, WA-C showed $51 \pm 4 \%(P<0.001 ; n=18)$, WA-P inv ${ }^{-} 41 \pm 3 \%$ $(P<0.001 ; n=6)$ and WA-C inv $^{-} 36 \pm 3 \% \quad(P<0.001$; $n=6)$ of the initial resistance, $48 \mathrm{~h}$ p.i. Thus, both invasindeficient mutants caused even a slightly more pronounced effect than the other Yersinia-strains $(P<0.05, P<0.001)$. Invasion-deficiency was proved in a gentamicin-protection assay (data not shown). 


\section{Cytotoxicity and Apoptosis}

To examine, whether a loss of epithelial cells also contributes to barrier dysfunction, the amount of necrotic and apoptotic cells was determined. Y. enterocolitica-induced cytotoxicity was assessed by measuring the release of LDH from epithelial cells. In controls, a LDH-release of $1.1 \pm 0.1 \%$ was detected $(n=12)$. In supernatants of infected cell monolayers, LDH concentrations were increased $(3.8 \pm 0.8 \%, P<0.01 ; n=12)$. However, the amount of LDH released did not correlate with the decrease of $\mathrm{R}^{\mathrm{t}}$ (Figure 7a). Mutant-strains WA-C, WA-P a
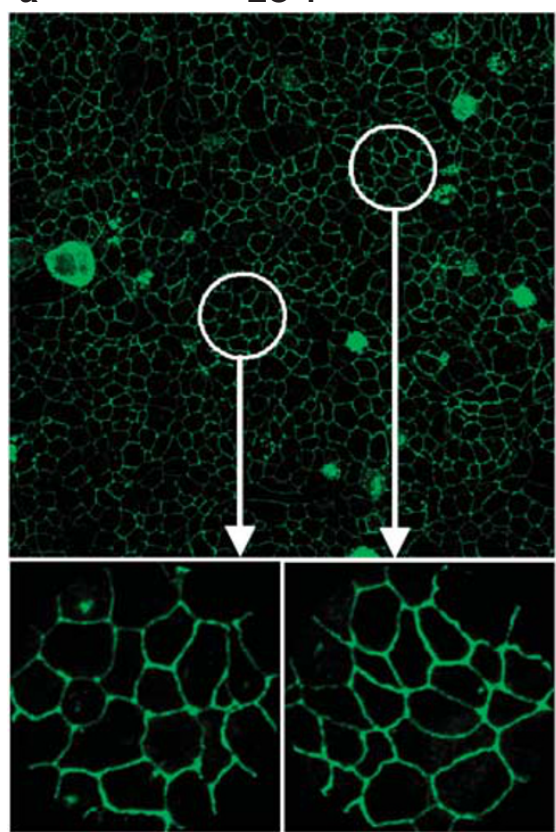

leaky

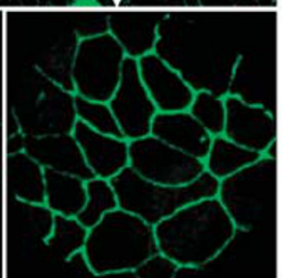

intact b
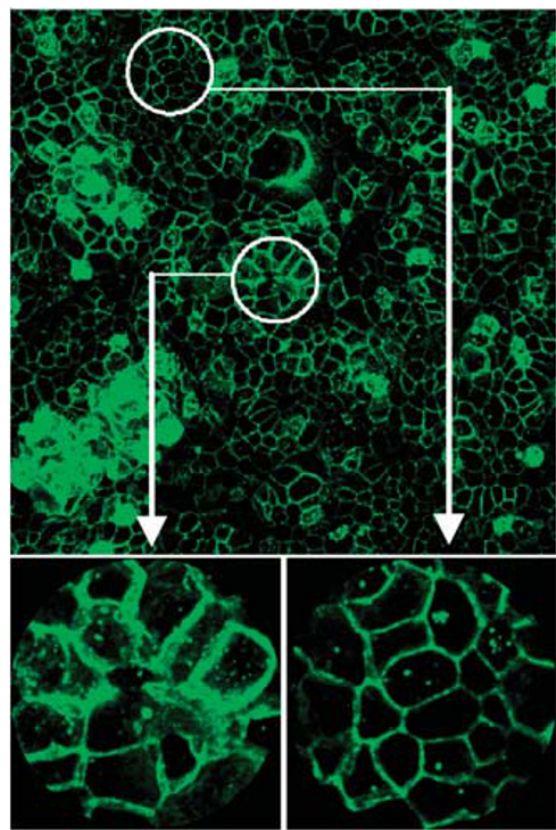

leaky

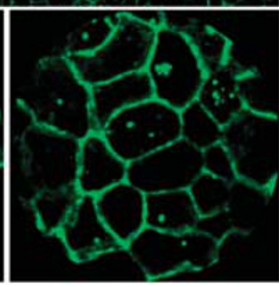

intact

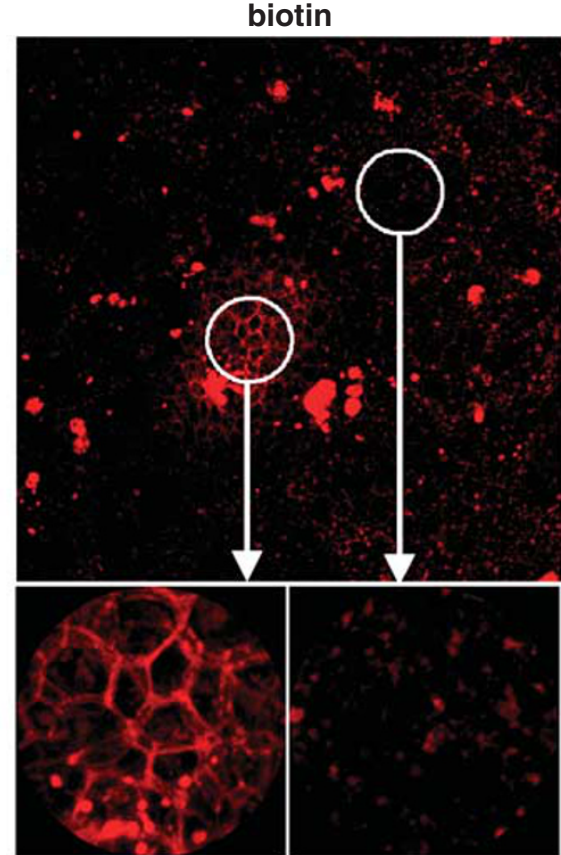

leaky

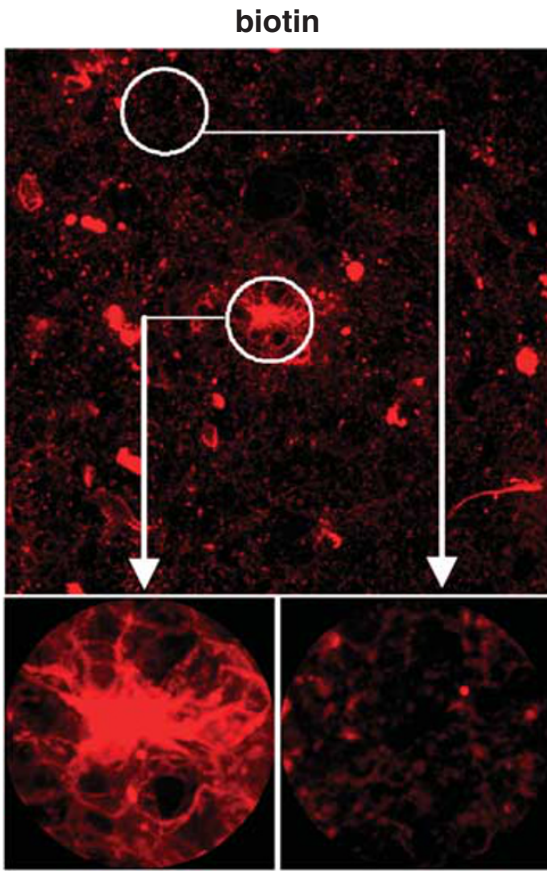

leaky intact

intact
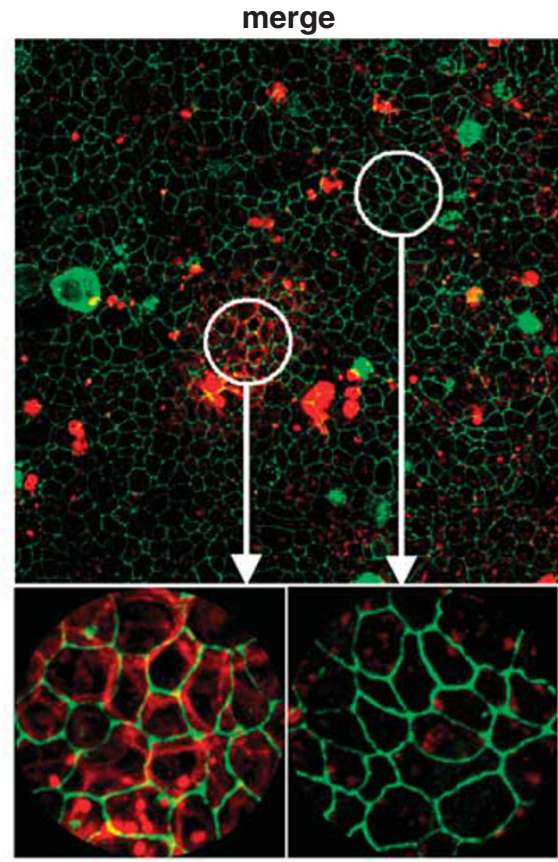

leaky

intact

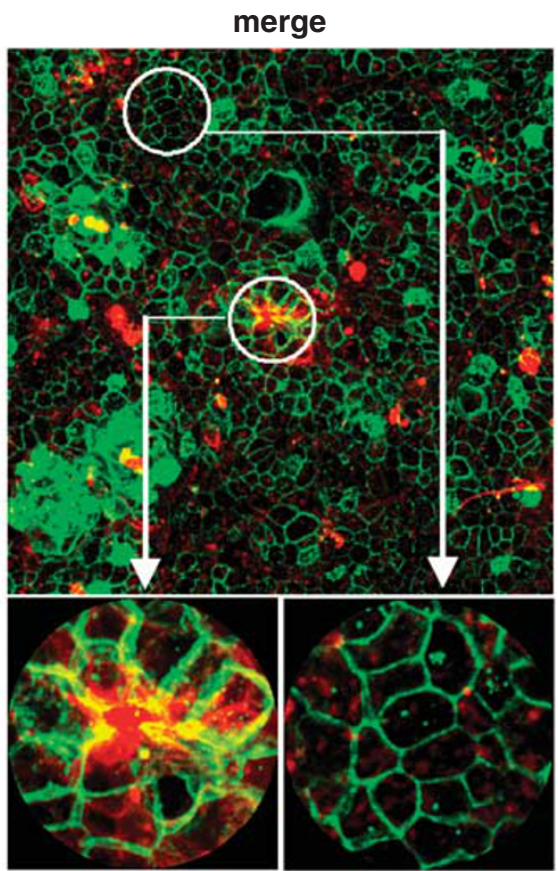

leaky

intact

Figure 4 Analyzes of tight junction proteins in leaky and intact regions by confocal laser scanning microscopy. The z-stack projections of infected monolayers displaying parallel biotinylation (red) and immunostaining for (a) ZO-1, (b) claudin-4 and (c) claudin-8 (green). 'Leaky regions' are characterized by an intense biotin permeation (red), which was absent in 'intact regions' that are characterized by lacking biotinylated cell boundaries. 
C
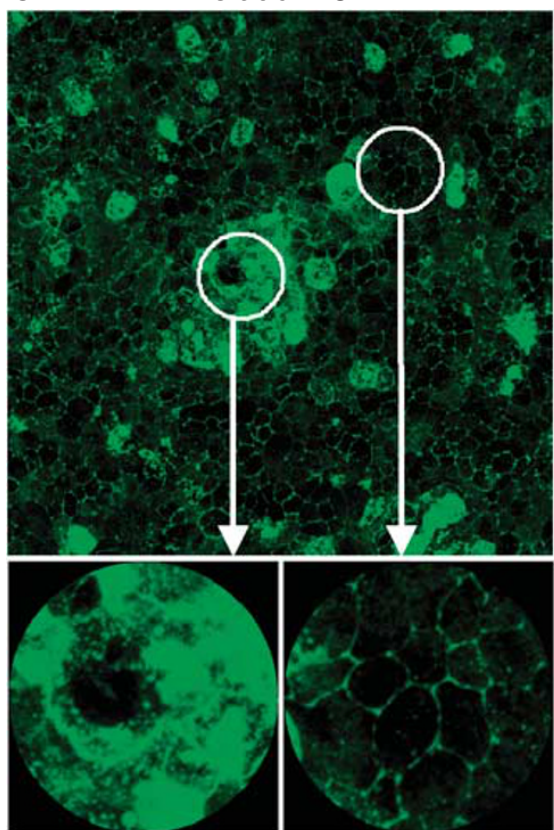

leaky

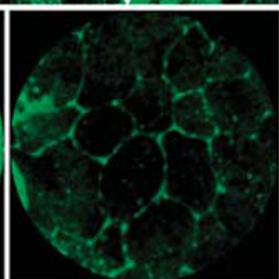

intact

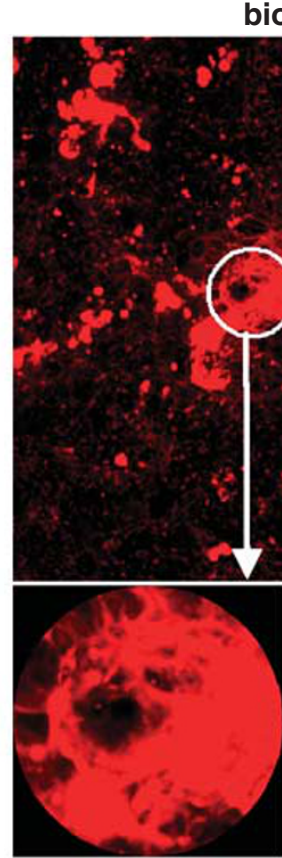

leaky biotin
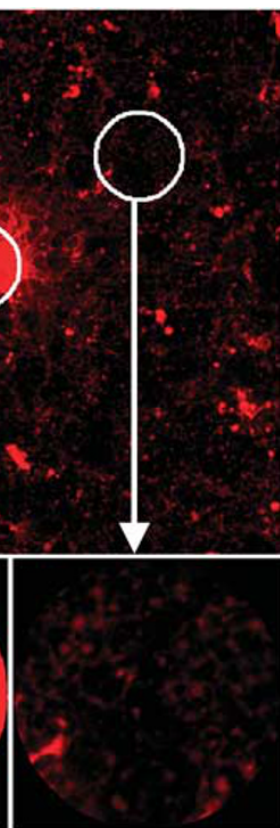

intact
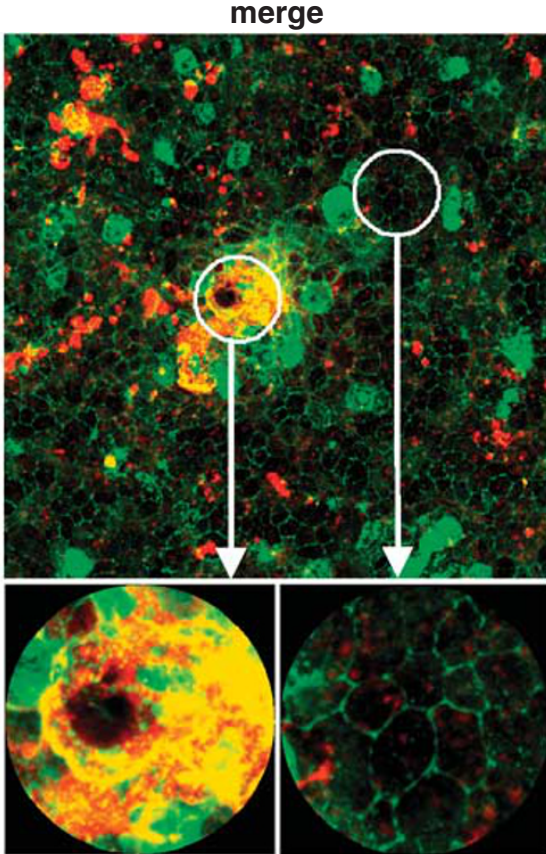

leaky

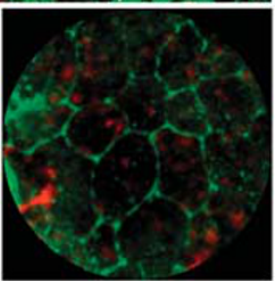

intact

Figure 4 Continued.

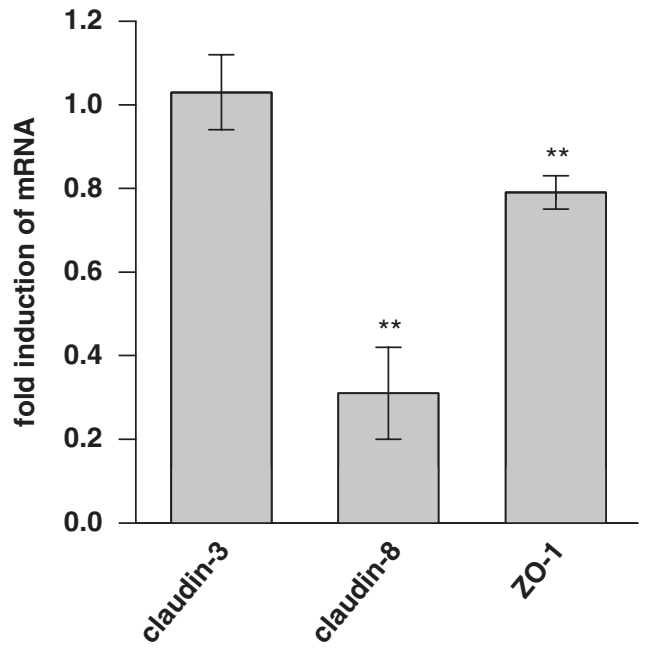

Figure 5 Quantification of claudin-3 and -8 and ZO-1-mRNA-level. RNA was prepared at $6 \mathrm{~h}$ p.i. from infected and control monolayers. mRNA expression of claudin-3, claudin-8 and ZO-1 were determined by qRT-PCR and GAPDH was used for normalization. Data are means \pm s.e.m. of $x$-fold induction over controls $\left(n=5,{ }^{*} \mathrm{P}<0.01\right.$ compared with untreated control).

inv $^{-}$and WA-C inv $^{-}$induced LDH-levels similar to wildtype yersiniae (data not shown).

Apoptosis induction was quantified in HT-29/B6 monolayers by TUNEL staining. Infection with Y. enterocolitica had no impact on epithelial apoptosis (Figure 7b). The number of apoptotic cells detected in infected monolayers was not significantly different from that in controls $(2.5 \pm 0.9 \%$ in infected monolayers vs $3.6 \pm 0.7 \%$ in controls; $n=5$ ).

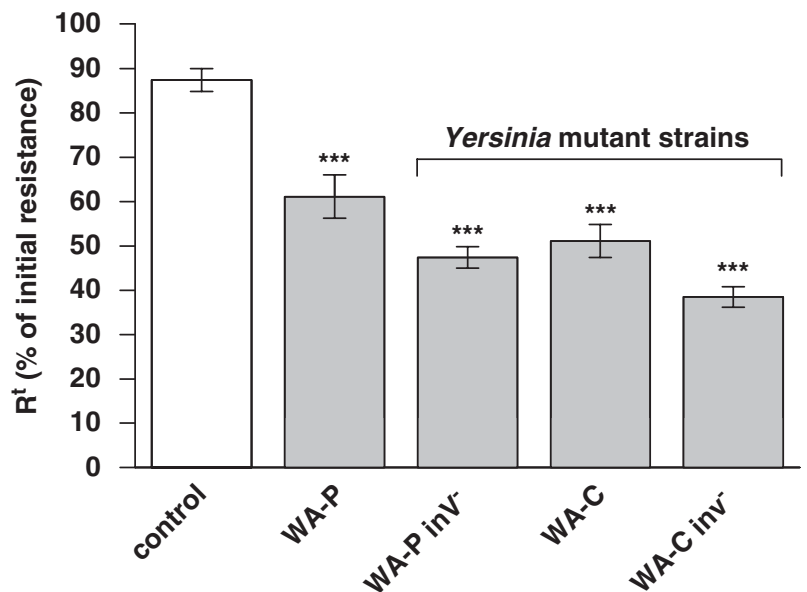

Figure 6 Effect on $\mathrm{R}^{\mathrm{t}}$ after infection of HT-29/B6 monolayers with mutant strains. WA-C (PYV cured), WA-P inv ${ }^{-}$(invasion-deficient) or WA-C inv ${ }^{-}$ (PYV cured and invasion-deficient) derived from the $Y$. enterocolitica 08

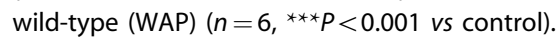

For comparison, tumor necrosis factor $\alpha$ and interleukin-13 as a positive control induced an increase in apoptosis to about $17.8 \pm 0.7 \%(n=2)$.

\section{Induction of Signaling Pathways}

Recently, it was published that the Y. enterocolitica heat-stable enterotoxin (Y-STa) stimulates intracellular inositol trisphosphate (IP3) very quickly, which binds to the IP3 receptor 

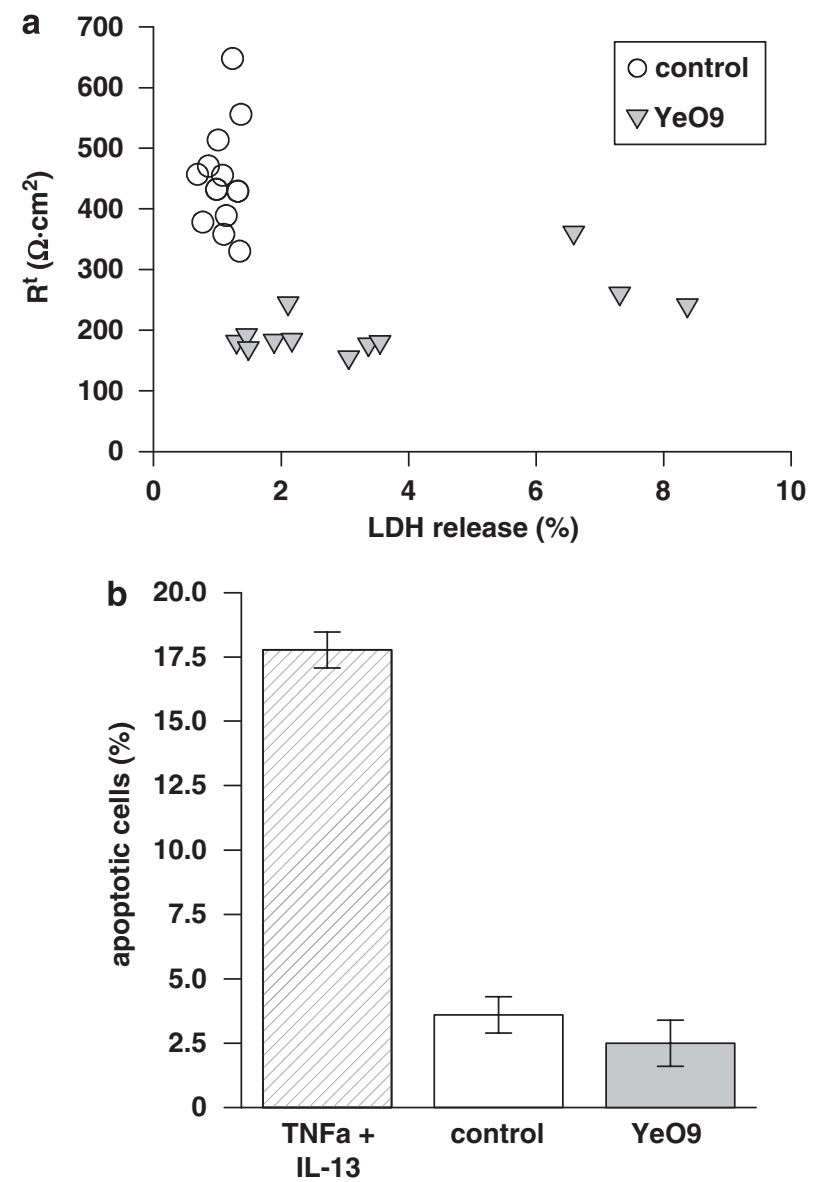

Figure $7 Y$. enterocolitica-induced cytotoxicity. (a) Induction of necrosis in HT-29/B6 monolayers was determined by measurement of LDH release. Furthermore, LDH release from controls and infected monolayers were shown in correlation to the corresponding $\mathrm{R}^{\mathrm{t}}$ values at $48 \mathrm{~h}$ p.i. $(n=12)$. (b) Induction of apoptosis was monitored by TUNEL-staining and subsequent fluorescence-activated cell sorting $(n=5)$. HT-29/B6 monolayers treated with a combination of tumor necrosis factor $\alpha$ and interleukin-13 served as positive controls.

and mobilizes intracellular calcium in rat intestinal epithelial cells. ${ }^{38,39}$ Accordingly, we examined in how far a calciumresponse could be stimulated in HT-29/B6 by cultured $Y$. enterocolitica using fura-2AM. As we expected a putative calcium-response very quickly, we measured intracellular calcium levels, about a duration, of $60 \mathrm{~min}$ after infection. As already described by Saha $e a^{39}$ the potent IP3 agonist ATP $^{40}$ was applied as positive control and induced a quick 4.2fold $\pm 0.6(n=3) \quad$ rise in calcium from baseline levels $(221.6 \mathrm{nM} \pm 37, n=9)$ in HT-29/B6. However, when monolayers were perfused with bacterial suspension (vital or heatinactivated yersiniae) at 37 or $27^{\circ} \mathrm{C}$ no calcium mobilization occurred. Long-term effects were ruled out, as chelating intracellular calcium with BAPTA-AM before infection did not influence the course of $\mathrm{R}^{\mathrm{t}}$.

In the following, inhibitor studies were performed to examine, whether $Y$. enterocolitica affected any signaling path- way, which in turn regulates TJ protein expression directly. A detailed description of all inhibitors tested is shown in Supplementary Information, Supplementary Table S2. It is interesting that only the c-Jun terminal kinase inhibitors SP600125 or JNKi1 partially influenced the Y. enterocoliticainduced decrease in $\mathrm{R}^{\mathrm{t}}$. All other inhibitors could not stop or reduce the drop of resistance.

In Yersinia-infected monolayers treated with SP600125 $\mathrm{R}^{\mathrm{t}}$ was reduced to $33 \pm 6.5 \%$ from initial resistance within $48 \mathrm{~h}$ p.i. This was comparable to infected monolayers not treated with SP600125 which amounted to $32 \pm 0.8 \% \quad(n=11)$. SP600125 diminished $\mathrm{R}^{\mathrm{t}}$ to $61 \pm 0.7 \%$ vs control $78 \pm 3.3 \%$ $(P<0.01 ; n=11)$ masking a supposedly reduced decrease in $\mathrm{R}^{\mathrm{t}}$ (Figure 8a). Thus, an other JNK-inhibitor, JNKil, was examined, which had no effect on $\mathrm{R}^{\mathrm{t}}$ itself. JNKil reduced the Y. enterocolitica-induced decrease in $\mathrm{R}^{\mathrm{t}}$ by $9 \pm 2 \%(P<0.01$; $n=4$ ) (Figure 8b).

As shown in Figures $8 \mathrm{c}$ and d JNK-phosphorylation was enhanced at $10 \mathrm{~min}$ after $Y$. enterocolitica infection $(P<0.01$; $n=5$ ), whereas other MAP kinases were not involved (Supplementary Figure S3). In order to clarify, whether TJ protein expression was affected by the inhibition of JNK protein level, ZO- 1 and claudin- $3,-4,-5$ and -8 were examined by western blot (Figure 8e). Inhibition of JNK resulted in a recovery of claudin-8 expression, whereas all other TJ proteins tested were not affected. Treatment with SP600125 restored claudin- 8 protein level to $90 \pm 6 \%$ compared with $66 \pm 10 \%$ in untreated infected monolayers $(P<0.05 ; n=5)$ and $96 \pm 9 \%$ in control monolayers treated with SP60025 (Figure 8f). Similar effects on claudin-8 expression were observed with JNKi1 (Supplementary Figure S4). However, biotinylation and claudin-8 immunostaining of JNKil-treated infected monolayers revealed that JNK-inhibition could not influence the claudin-8 redistribution process within leaky regions (data not shown).

Because the WA-C mutant strain decreased claudin-8 protein level as well at $48 \mathrm{~h}$ p.i. (Supplementary Figure S5), the observed effects on JNK were independent from the PYV.

\section{DISCUSSION}

$Y$. enterocolitica infection is associated with diarrhea and especially children can suffer from severe enterocolitis. ${ }^{41}$ However, the inherent mechanisms and morphological epithelial alterations are far from being clear. Until now, only an epithelial barrier disturbance was identified as a prominent feature in a mouse model. ${ }^{6}$ This phenomenon could indeed contribute to diarrhea and may subsequently lead to other pathological events frequently observed with $Y$. enterocolitica infection, eg arthritis (cf. below). The epithelial changes responsible for this barrier defect, however, have not been elucidated so far.

\section{Epithelial Changes in $Y$. enterocolitica Infection}

As known from previous studies HT-29/B6 is a suitable model for studying pathogen-induced barrier dysfunction. ${ }^{8,9}$ 

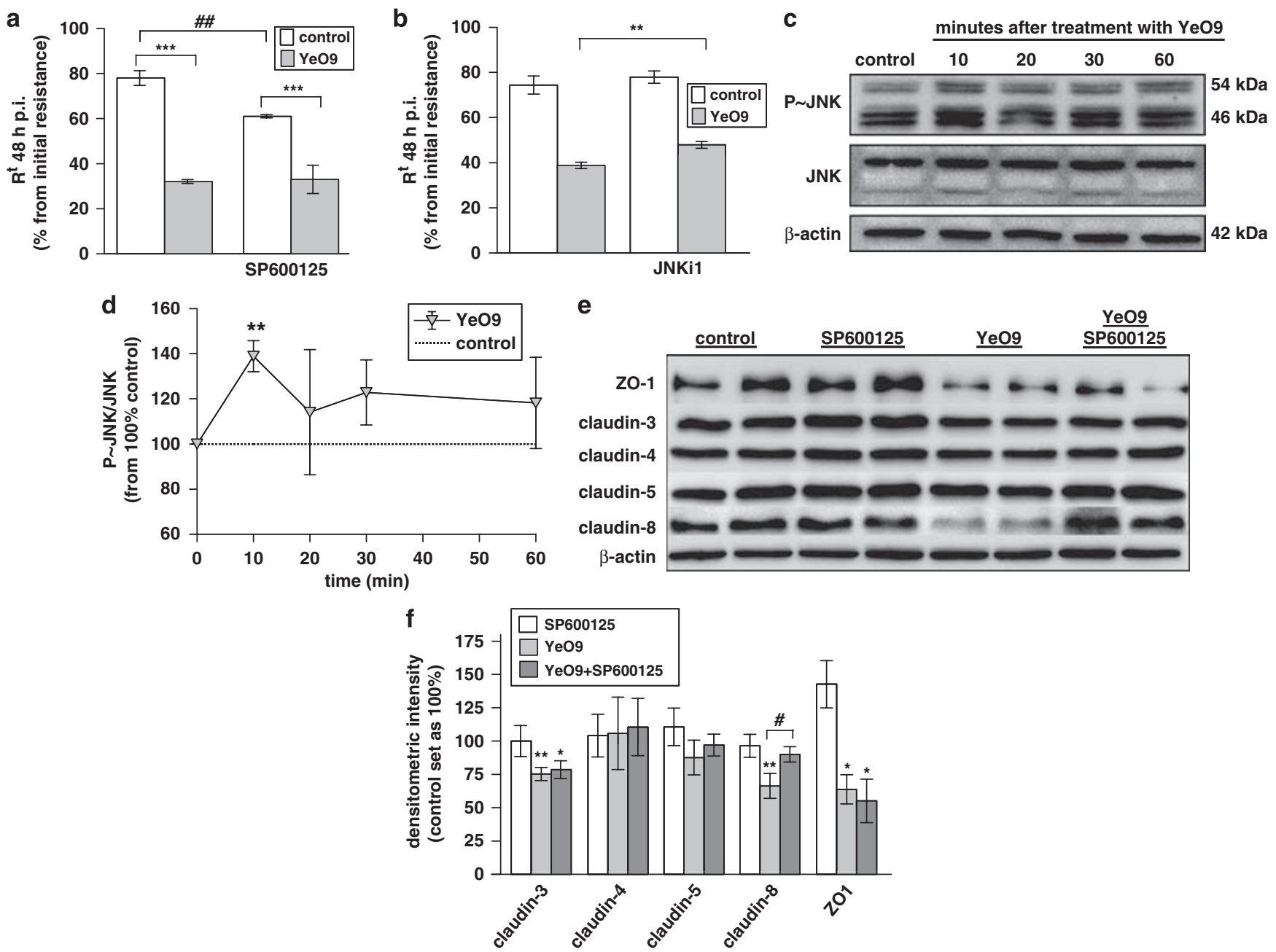

Figure 8 Regulation of claudin-8 by JNK. HT-29/B6 monolayers were treated with JNK-inhibitors SP600125 or JNKi1 before infection. (a) In controls SP600125 caused a significant drop in $R^{t}$ from initial resistance within $48 \mathrm{~h}$, masking a supposedly reduced decrease in $R^{t}$ in $Y$. enterocolitica-infected monolayers $(n=11)$. (b) Application of JNKi1 had no effect on $R^{t}$ in controls and an attenuation in $Y$. enterocolitica-induced $R^{t}$ drop became obvious $(P<0.01 ; n=4)$. (c) Western blot analyses showed enhanced JNK-phosphorylation at 10 min after infection. (d) Time course of JNK-phosphorylation in HT-29/B6 after $Y$. enterocolitica infection. Signals from all conditions were quantified by densitometry and the ratio of $\mathrm{P} \sim \mathrm{JNK}$ and JNK was determined. Values from untreated controls were set as $100 \%$ and compared with signals from Y. enterocolitica stimulation. (e) Inhibition of JNK signalling restored claudin-8 protein level significantly, but had no impact on other TJ proteins probed $(n=5)$. (f) Densitometric quantification of TJ proteins after normalization with $\beta$-actin ( $n=5$ or $7 ;{ }^{\star} P<0.05$ and ${ }^{* *} P<0.01$ compared with untreated control, ${ }^{\#} P<0.05$ compared with inhibitor treatment).

In the present study we found that barrier function was significantly changed in HT-29/B6 monolayers by Y. enterocolitica infection, indicated by resistance and flux measurements. As besides resistance only fluxes of paracellular markers with small hydrodynamic radii were enhanced (3.6 and $4.5 \AA$ ), we propose Y. enterocolitica to trigger TJ regulation. This was also directly supported by data from two-path impedance spectroscopy.

\section{Regional Leakiness in The HT-29/B6 Monolayers after $Y$. enterocolitica Infection}

One very important aspect of the present study is the detection of focal, unequally distributed barrier defects surrounded by 'intact regions' within infected monolayers. Functionally, these 'leaky regions' are characterized by an increased conductivity that could be detected by conductance scanning. Structurally, this regional loss in epithelial barrier function comprises changes in $\mathrm{TJ}$ protein assembly as visualized by confocal laser scanning microscopy. Within these 'leaky regions' TJ proteins were re-distributed off the TJ into subapical intracellular compartments.

\section{Role of Claudins in $Y$. enterocolitica Infection}

In addition to being distributed off the TJ, TJ proteins can also be downregulated in their expression level. In general, several of the 24 claudins have barrier function and elevate $\mathrm{R}^{\mathrm{t}}$. Barrier-forming claudins present in small or large intestine are especially claudin- $1,-3,-4,-5$ and $-8 .{ }^{42}$ Within these, claudin-8 is a well-established barrier former of the TJ. ${ }^{43}$ In addition to its re-distribution process, claudin- 8 was found 
to be strongly reduced on protein- and mRNA-level in favour of expression regulation from the gene. Other claudins create cation selective pores with a concomitant decrease in resistance, eg claudin- $2^{44}$ and $-10 \mathrm{~b} \cdot{ }^{45}$ However, claudin-2 is not present in the intestine under physiological conditions and is even slightly up-regulated during inflammation or epithelial restitution. The role of claudin-10 for intestinal barrier function is less well defined, as it was so far studied only in the kidney and its functional role has to be assumed to depend on the specific environment of the other TJ proteins in the intestine. Thus, taken together, claudin- $3,-4$ and -8 which are reduced or/and re-distributed off the TJ by $Y$. enterocolitica infection are the most prominent candidates to contribute to the barrier dysfunction observed in the present study. This is in agreement with other investigations describing different enteric pathogens to cause barrier dysfunction by affecting claudins. ${ }^{23,24,46}$

\section{Role of ZO-1}

ZO-1 protein expression was substantially diminished in infected monolayers. This membrane-associated scaffolding protein ${ }^{47}$ couples the major transmembranal barrier proteins as claudins, ${ }^{48}$ occludin,${ }^{49,50}$ tricellulin $^{18}$ and JAM-A ${ }^{17,51}$ to myosin-actin cytoskeleton. ${ }^{52}$ As ZO-1 is not a strand component it has no direct effect on transepithelial resistance, but it is not unlikely that a reduction of the ZO-1 anchor can result in a disassembly of barrier relevant claudins from the TJ strands. ${ }^{8}$

\section{TJ Ultrastructure by Freeze Fracture Electron Microscopy}

To all of our experimental experience, it is unlikely that such critically altered cell contacts like the 'leaky regions' would yield freeze fractures fulfilling the morphological criteria of intact strands. Therefore, we presume that the identified strands of infected cells represent 'intact regions'. These TJ strands, however, were not significantly different to controls in any parameter of our morphometric analysis. This finding is in full accord with the conductance scanning data, which yielded in 'intact regions' no significant difference in ion conductance between controls and Y. enterocolitica-infected cells (Figure $2 b$ ).

\section{Necrosis and Apoptosis Induction by $Y$. enterocolitica}

It is established that the loss of enterocytes can contribute to the leakiness of intestinal epithelia, as eg apoptotic events in the epithelium can increase the contribution of paracellular pathways to the overall epithelial permeability. ${ }^{7,37}$ However, $Y$. enterocolitica did not induce apoptosis but epithelial necrosis, indicated by an increase in LDH release. $Y$. enterocolitica-derived cytotoxicity has already been investigated in different tissues. The pYV-encoded YopP protein is essential for the induction of apoptosis in macrophages ${ }^{53}$ and simultaneously induces caspase-dependent apoptotic and caspase-independent necrotic cell death in dendritic cells. ${ }^{54,55}$ In Hep2 cells, apoptosis has been shown to be invasin induced. ${ }^{56}$ In contrast, $Y$. enterocolitica did not elevate the apoptotic rate in HT-29/B6 monolayers, but increased the level of necrotic cells. As LDH-levels were not diminished in mutant strain WA-C, WA-P inv ${ }^{-}$and WA-C inv $^{-}$exposed monolayers when compared with wild-type yersiniae, cytotoxicity has to be assumed to be independent from invasin or Yop-proteins. Although necrotic cell death is very likely to contribute to leakiness, we did not find a correlation of LDH-release and $\mathrm{R}^{\mathrm{t}}$-decrease $48 \mathrm{~h}$ after infection. One possible explanation is that $Y$. enterocolitica-induced necrotic leaks are properly closed by surrounding cells. Otherwise, it may be possible that barrier dysfunction from $Y$. enterocolitica-infection is triggered by the induction of necrosis that could end up in proteolytic cleavage of TJ proteins in epithelial cells, a phenomenon that is known eg from conditions with induction of apoptosis. ${ }^{57}$

\section{Mechanisms of Interaction}

It is interesting that the barrier function was only affected by viable bacteria and not by supernatants of cultured Y. enterocolitica. Other bacteria as eg Vibrio cholerae secrete toxins that disturb barrier function, namely the zonula occludens toxin. ${ }^{23}$ Also, production and release of hemolysins as in the case of E. coli O4 represent an example for barrier modification by soluble factors. ${ }^{9}$ However, Y. enterocolitica supernatants or lysates were not effective. Accordingly, we do not expect toxins or lipopolysaccharides to be involved. The role of the Yersinia heat-stable enterotoxin, which is only produced below $30^{\circ} \mathrm{C}$ in vitro, ${ }^{5}$ is controversially discussed. Saha et $a l^{38,39}$ showed Y-STa to stimulate IP3-level quickly resulting in calcium-mobilization by IP3R in vitro. We did not find vital $Y$. enterocolitica to stimulate a calcium-dependent response in HT-29/B6 cells.

Furthermore, the two mutant strains in our study still exhibited the barrier-disturbing effect. Thus, the barrier effect is independent of both invasin-mediated internalization and expression of the Yersinia pYV. These results differ from mechanisms described for Yersinia pseudotuberculosis, a close relative of $Y$. enterocolitica. Here, the plasmid encoded effector protein YopE of $Y$. pseudotuberculosis was shown to interfere with $\mathrm{F}$-actin re-arrangement and subsequently to affect TJ structure and function. ${ }^{58}$ However, Y. enterocolitica is more frequently associated with diarrhea than its close relative. Therefore, it is not unlikely that both bacteriae differ in their virulence factors for barrier perturbation.

Several studies revealed $Y$. enterocolitica to induce proinflammatory host cell response or to counteract host defense mechanisms by interfering with eukaryotic signal transduction pathways. For example, Yersinia invasin activates p38 and JNK in epithelial cells, which, together with MEK1, mediate the transcriptional activation of the interleukin- 8 gene. ${ }^{59}$ YopP induces cell death by the inhibition of MAPKs, predominantly p38 and JNK, in dendritic cells but not in macrophages. ${ }^{60}$ In this study, we found Y. enterocolitica to induce JNK-activation resulting in a strong decrease in 
claudin-8 expression that was independent from Yops. As also invasin-deficient mutants caused a pronounced decrease in $\mathrm{R}^{\mathrm{t}}$ compared with wild-type strains, we do not expect invasin to be responsible for the JNK-activation in this setting. Although JNK inhibition restored claudin- 8 protein level in infected monolayers to normal, it had no influence on claudin-8 delocalization within leaky regions. This may explain the slight effect of JNK-inhibition on $\mathrm{R}^{\mathrm{t}}$. Moreover, $Y$. enterocolitica exerts a multimodal effect on epithelial monolayers. Consequently, it is not surprising that restitution of only one single component could only partially restore barrier function. Modulation of TJ protein expression by different signaling cascades has been described for different cell lines and conditions. ${ }^{61-63}$ However, so far it is not clear, which signaling cascades alter the expression of ZO-1 and other claudins than claudin-8 in Y. enterocolitica infection. Moreover, the type of interaction remains speculative. A receptor-mediated interaction between vital bacteria and epithelial cells might be hypothesized. Claudin- 3 and -4 have been described to serve as receptors for the Clostridium perfringens enterotoxin, thereby inducing barrier dysfunction. ${ }^{24}$ Whether $Y$. enterocolitica directly interacts with TJ proteins remains uncertain. It seems more probable that the patchy pattern of the barrier defect could be caused by a not equally distributed access of the bacteria to the epithelial layer. This might depend on receptor exposure by single specialized cells within the epithelial monolayer or a discontinuous protective mucus layer on the apical surface of the cells.

\section{Barrier-Disturbing Mechanisms of $Y$. enterocolitica Infection}

A leak flux mechanism of diarrhea as a result of the impaired barrier function had been proposed by our group for Y. enterocolitica-infection. ${ }^{6}$ In support of this, in the present study on HT-29/B6 cells we identified the underlying mechanisms of this barrier defect and confirmed the important role of this pathomechanism. Other diarrheal mechanisms as active ion secretion or malabsorption were neither detected in mouse small intestine nor in HT-29/B6 cells. This may also explain why $Y$. enterocolitica is not that often detected as an inducer of diarrhea and more frequently recognized in the clinic as a source of extraintestinal manifestations. In this context it should be mentioned that an infection-dependent increase in luminal antigen uptake resulting from intestinal barrier dysfunction has been proposed to trigger arthritis ${ }^{64}$ and inflammatory bowel diseases. ${ }^{65}$

\section{Conclusion}

In the present study, we introduced mechanisms of barrier dysfunction relevant during $Y$. enterocolitica infection. This pathogen exerts two different pathomechanisms, which both can cause leak flux diarrhea and seem not to depend on the typical Y. enterocolitica virulence factors, such as enterotoxin, invasins or Yops. On one hand, Y. enterocolitica induces 'leaky regions' due to the appearance of local TJ protein changes, characterized by $\mathrm{TJ}$ protein reduction and re-distribution of the TJ. On the other hand, necrotic cell loss takes place and may contribute to the barrier loss.

Supplementary Information accompanies the paper on the Laboratory Investigation website (http://www.laboratoryinvestigation.org)

\section{ACKNOWLEDGEMENTS}

This work was supported by DFG Research Unit FOR 721. We thank Ralf Ignatius for kindly providing the clinical $Y$. enterocolitica O9 isolate. Furthermore, we thank D. Sorgenfrei, S. Schön and I.M. Lee for their excellent technical assistance. DFG Grant FOR 721.

\section{DISCLOSURE/CONFLICT OF INTEREST}

The authors declare no conflict of interest.

1. Smego RA, Frean J, Koornhof HJ. Yersiniosis I: microbiological and clinicoepidemiological aspects of plague and non-plague Yersinia infections. Eur J Clin Microbiol Infect Dis 1999;18:1-15.

2. Koornhof HJ, Smego Jr RA, Nicol M. Yersiniosis. II: The pathogenesis of Yersinia infections. Eur J Clin Microbiol Infect Dis 1999;18:87-112.

3. Grassl GA, Bohn E, Muller $Y$, et al. Interaction of Yersinia enterocolitica with epithelial cells: invasin beyond invasion. Int J Med Microbiol 2003:293:41-54.

4. Schiemann DA. An enterotoxin-negative strain of Yersinia enterocolitica serotype 0:3 is capable of producing diarrhea in mice. Infect Immun 1981;32:571-574.

5. Mikulskis AV, Delor I, Thi $\mathrm{VH}$, et al. Regulation of the Yersinia enterocolitica enterotoxin Yst gene. Influence of growth phase, temperature, osmolarity, $\mathrm{pH}$ and bacterial host factors. Mol Microbiol 1994;14:905-915.

6. Gogarten W, Kockerling A, Fromm M, et al. Effect of acute Yersinia enterocolitica infection on intestinal barrier function in the mouse. Scand J Gastroenterol 1994;29:814-819.

7. Epple HJ, Schneider T, Troeger $\mathrm{H}$, et al. Impairment of the intestinal barrier is evident in untreated but absent in suppressively treated HIVinfected patients. Gut 2009;58:220-227.

8. Bucker $\mathrm{R}$, Troeger $\mathrm{H}$, Kleer J, et al. Arcobacter butzleri induces barrier dysfunction in intestinal HT-29/B6 cells. J Infect Dis 2009;200:756-764.

9. Troeger H, Richter JF, Beutin L, et al. Escherichia coli alpha-haemolysin induces focal leaks in colonic epithelium: a novel mechanism of bacterial translocation. Cell Microbiol 2007;9:2530-2540.

10. Berkes J, Viswanathan VK, Savkovic SD, et al. Intestinal epithelia responses to enteric pathogens: effects on the tight junction barrier, ion transport, and inflammation. Gut 2003;52:439-451.

11. Anderson JM. Molecular structure of tight junctions and their role in epithelial transport. News Physiol Sci 2001;16:126-130.

12. Tsukita $S$, Furuse $M$, Itoh $M$. Multifunctional strands in tight junctions. Nat Rev Mol Cell Biol 2001;2:285-293.

13. Anderson JM, Van Itallie CM. Tight junctions and the molecular basis for regulation of paracellular permeability. Am J Physiol 1995;269 (4 Part 1):G467-G475.

14. Madara JL. Regulation of the movement of solutes across tight junctions. Annu Rev Physiol 1998;60:143-159.

15. Furuse $M$, Hirase $T$, Itoh $M$, et al. Occludin: a novel integral membrane protein localizing at tight junctions. J Cell Biol 1993;123(6 Part 2): 1777-1788

16. Furuse $M$, Fujita $K$, Hiiragi $T$, et al. Claudin-1 and -2: novel integral membrane proteins localizing at tight junctions with no sequence similarity to occludin. J Cell Biol 1998;141:1539-1550.

17. Martin-Padura I, Lostaglio S, Schneemann M, et al. Junctional adhesion molecule, a novel member of the immunoglobulin superfamily that distributes at intercellular junctions and modulates monocyte transmigration. J Cell Biol 1998;142:117-127.

18. Ikenouchi J, Furuse $\mathrm{M}$, Furuse $\mathrm{K}$, et al. Tricellulin constitutes a novel barrie at tricellular contacts of epithelial cells. J Cell Biol 2005;171:939-945.

19. Turner JR. 'Putting the squeeze' on the tight junction: understanding cytoskeletal regulation. Semin Cell Dev Biol 2000;11:301-308. 
20. Gonzalez-Mariscal L, Betanzos A, Avila-Flores A. MAGUK proteins: structure and role in the tight junction. Semin Cell Dev Biol 2000;11:315-324.

21. Mitic LL, Van Itallie CM, Anderson JM. Molecular physiology and pathophysiology of tight junctions I. Tight junction structure and function: lessons from mutant animals and proteins. Am J Physiol Gastrointest Liver Physiol 2000;279:G250-G254.

22. Angelow S, Ahlstrom R, Yu AS. Biology of claudins. Am J Physiol Renal Physiol 2008;295:F867-F876.

23. Fasano A, Baudry B, Pumplin DW, et al. Vibrio cholerae produces a second enterotoxin, which affects intestinal tight junctions. Proc Natl Acad Sci USA 1991;88:5242-5246.

24. Sonoda N, Furuse M, Sasaki $H$, et al. Clostridium perfringens enterotoxin fragment removes specific claudins from tight junction strands: Evidence for direct involvement of claudins in tight junction barrier. J Cell Biol 1999;147:195-204.

25. Kreusel KM, Fromm M, Schulzke JD, et al. Cl- secretion in epithelial monolayers of mucus-forming human colon cells (HT-29/B6). Am J Physiol 1991;261(4 Part 1):C574-C582.

26. Heesemann J, Laufs R. Construction of mobilizable Yersinia enterocolitica virulence plasmid. J Bacteriol 1983;155:761-767.

27. Ruckdeschel K, Roggenkamp A, Schubert S, et al. Differential contribution of Yersinia enterocolitica virulence factors to evasion of microbicidal action of neutrophils. Infect Immun 1996;64:724-733.

28. Epple HJ, Kreusel KM, Hanski C, et al. Differential stimulation of intestinal mucin secretion by cholera toxin and carbachol. Pflugers Arch 1997;433:638-647

29. Rosenthal R, Choritz L, Zorn R, et al. Endothelin receptor B in trabecular meshwork. Exp Eye Res 2007;85:482-491.

30. Grynkiewicz G, Poenie M, Tsien RY. A new generation of $\mathrm{Ca}^{2+}$ indicators with greatly improved fluorescence properties. J Biol Chem 1985;260:3440-3450.

31. Krug SM, Fromm M, Gunzel D. Two-path impedance spectroscopy for measuring paracellular and transcellular epithelial resistance. Biophys J 2009;97:2202-2211.

32. Gitter AH, Bendfeldt K, Schulzke JD, et al. Leaks in the epithelial barrier caused by spontaneous and TNF-alpha-induced single-cell apoptosis. Faseb J 2000;14:1749-1753.

33. Madara JL, Stafford J. Interferon-gamma directly affects barrier function of cultured intestinal epithelial monolayers. J Clin Invest 1989;83:724-727.

34. Heller F, Florian P, Bojarski C, et al. Interleukin-13 is the key effector Th2 cytokine in ulcerative colitis that affects epithelial tight junctions apoptosis, and cell restitution. Gastroenterology 2005;129:550-564.

35. Amasheh S, Schmidt T, Mahn M, et al. Contribution of claudin-5 to barrier properties in tight junctions of epithelial cells. Cell Tissue Res 2005;321:89-96.

36. Krug SM, Amasheh S, Richter JF, et al. Tricellulin forms a barrier to macromolecules in tricellular tight junctions without affecting ion permeability. Mol Biol Cell 2009;20:3713-3724.

37. Bojarski C, Gitter AH, Bendfeldt K, et al. Permeability of human HT-29/ B6 colonic epithelium as a function of apoptosis. J Physiol 2001;535(Part 2):541-552.

38. Saha S, Gupta DD, Chakrabarti MK. Involvement of phospholipase C in Yersinia enterocolitica heat stable enterotoxin (Y-STa) mediated rise in intracellular calcium level in rat intestinal epithelial cells. Toxicon 2005;45:361-367.

39. Saha S, Chowdhury $P$, Mazumdar A, et al. Role of Yersinia enterocolitica heat-stable enterotoxin (Y-STa) on differential regulation of nuclear and cytosolic calcium signaling in rat intestinal epithelial cells. Cell Biol Toxicol 2009;25:297-308.

40. Berridge MJ. Inositol trisphosphate and calcium signalling. Nature 1993:361:315-325

41. Marriott DJ, Taylor S, Dorman DC. Yersinia enterocolitica infection in children. Med J Aust 1985;143:489-492.

42. Markov AG, Veshnyakova A, Fromm M, et al. Segmental expression of claudin proteins correlates with tight junction barrier properties in rat intestine. J Comp Physiol B 2010;180:591-598.

43. Yu AS, Enck AH, Lencer WI, et al. Claudin-8 expression in madin-darby canine kidney cells augments the paracellular barrier to cation permeation. J Biol Chem 2003;278:17350-17359.

44. Amasheh $\mathrm{S}$, Meiri N, Gitter $\mathrm{AH}$, et al. Claudin-2 expression induces cation-selective channels in tight junctions of epithelial cells. J Cell Sci 2002;115(Part 24):4969-4976.
45. Günzel D, Amasheh S, Pfaffenbach $\mathrm{S}$, et al. Claudin-16 affects transcellular Cl- secretion in MDCK cells. J Physiol 2009;587(Part 15):3777-3793.

46. Kohler H, Sakaguchi T, Hurley BP, et al. Salmonella enterica serova Typhimurium regulates intercellular junction proteins and facilitates transepithelial neutrophil and bacterial passage. Am J Physiol Gastrointest Liver Physiol 2007;293:G178-G187.

47. Funke L, Dakoji S, Bredt DS. Membrane-associated guanylate kinases regulate adhesion and plasticity at cell junctions. Annu Rev Biochem 2005;74:219-245.

48. Itoh $M$, Furuse $M$, Morita $K$, et al. Direct binding of three tight junctionassociated MAGUKs, ZO-1, ZO-2, and ZO-3, with the $\mathrm{COOH}$ termini of claudins. J Cell Biol 1999;147:1351-1363.

49. Furuse $M$, Itoh $M$, Hirase $T$, et al. Direct association of occludin with ZO-1 and its possible involvement in the localization of occludin at tight junctions. J Cell Biol 1994;127(6 Part 1):1617-1626.

50. Fanning $A S$, Jameson $B J$, Jesaitis $L A$, et al. The tight junction protein ZO-1 establishes a link between the transmembrane protein occludin and the actin cytoskeleton. J Biol Chem 1998;273: 29745-29753.

51. Rehder D, Iden S, Nasdala I, et al. Junctional adhesion molecule-a participates in the formation of apico-basal polarity through different domains. Exp Cell Res 2006;312:3389-3403.

52. Hartsock A, Nelson WJ. Adherens and tight junctions: structure, function and connections to the actin cytoskeleton. Biochim Biophys Acta 2008;1778:660-669.

53. Mills SD, Boland A, Sory MP, et al. Yersinia enterocolitica induces apoptosis in macrophages by a process requiring functional type III secretion and translocation mechanisms and involving YopP, presumably acting as an effector protein. Proc Natl Acad Sci USA 1997;94:12638-12643.

54. Erfurth SE, Grobner S, Kramer U, et al. Yersinia enterocolitica induces apoptosis and inhibits surface molecule expression and cytokine production in murine dendritic cells. Infect Immun 2004;72: 7045-7054.

55. Grobner S, Autenrieth SE, Soldanova I, et al. Yersinia YopP-induced apoptotic cell death in murine dendritic cells is partially independent from action of caspases and exhibits necrosis-like features. Apoptosis 2006;11:1959-1968.

56. Superti F, Pietrantoni A, Di Biase AM, et al. Inv-mediated apoptosis of epithelial cells infected with enteropathogenic Yersinia: a protective effect of lactoferrin. Res Microbiol 2005;156:728-737.

57. Bojarski C, Weiske J, Schoneberg T, et al. The specific fates of tight junction proteins in apoptotic epithelial cells. J Cell Sci 2004;117(Part 10):2097-2107.

58. Tafazoli F, Holmstrom A, Forsberg A, et al. Apically exposed, tight junction-associated beta1-integrins allow binding and YopE-mediated perturbation of epithelial barriers by wild-type Yersinia bacteria. Infect Immun 2000;68:5335-5343.

59. Grassl GA, Kracht M, Wiedemann A, et al. Activation of NF-kappaB and IL-8 by Yersinia enterocolitica invasin protein is conferred by engagement of Rac1 and MAP kinase cascades. Cell Microbiol 2003;5:957-971.

60. Adkins I, Schulz S, Borgmann S, et al. Differential roles of Yersinia outer protein P-mediated inhibition of nuclear factor-kappa B in the induction of cell death in dendritic cells and macrophages. J Med Microbiol 2008;57(Part 2):139-144.

61. Mankertz J, Amasheh M, Krug SM, et al. TNFalpha up-regulates claudin-2 expression in epithelial HT-29/B6 cells via phosphatidylinositol-3-kinase signaling. Cell Tissue Res 2009;336:67-77.

62. Carrozzino F, Pugnale $P$, Feraille $E$, et al. Inhibition of basal p38 or JNK activity enhances epithelial barrier function through differential modulation of claudin expression. Am J Physiol Cell Physiol 2009;297: C775-C787.

63. Naydenov NG, Hopkins AM, Ivanov Al. c-Jun N-terminal kinase mediates disassembly of apical junctions in model intestinal epithelia. Cell Cycle 2009;8:2110-2121.

64. Sartor RB. Importance of intestinal mucosal immunity and luminal bacterial cell wall polymers in the aetiology of inflammatory joint diseases. Baillieres Clin Rheumatol 1989;3:223-245.

65. Saebo A, Vik E, Lange OJ, et al. Inflammatory bowel disease associated with Yersinia enterocolitica O:3 infection. Eur J Intern Med 2005;16: 176-182. 